Federal Reserve Bank of Dallas

Globalization and Monetary Policy Institute

Working Paper No. 252

http://www.dallasfed.org/assets/documents/institute/wpapers/2015/0252.pdf

\title{
Simple Models to Understand and Teach Business Cycle Macroeconomics for Emerging Market and Developing Economies*
}

\author{
Roberto Duncan \\ Ohio University
}

September 2015

\begin{abstract}
The canonical neoclassical model is insufficient to understand business cycle fluctuations in emerging market and developing economies (EMDEs). I reformulate the models proposed by Aguiar and Gopinath (2007) and Neumeyer and Perri (2005) in simple settings that can be used to do back-of-the-envelope analysis and teach business cycle macroeconomics for EMDEs at the undergraduate level. The simplified models are employed for qualitatively explaining facts such as the countercyclicality of the trade balance and the real interest rate, and the higher volatility of output, consumption, and real wages compared with those observed in advanced countries. Simple extensions can be used to understand other empirical facts such as large capital outflows and output drops, small government spending multipliers, the cyclical behavior of prices, and the negative association between currency depreciations and output.
\end{abstract}

JEL codes: A22, E32, F32

\footnotetext{
* Roberto Duncan, Department of Economics, Ohio University, Office: 349 Bentley Annex, Athens, OH 45701. 740-593-0181. duncanr1@ohio.edu.. I am grateful to Rose Rossiter, Patricia Toledo, Alfredo Baldini, an anonymous referee, the editor, and seminar participants at Ohio University and the Conference on Teaching and Research in Economic Education for useful suggestions and comments. The author is also thankful for research assistance provided by Adanu Fafali, Soo Hyun Hwang, Sovanara (Johnny) Im, Lingqiao Tang, Md Shah Jalal Uddin, and Levi Weible. All errors are mine. The views in this paper are those of the author and do not necessarily reflect the views of the Federal Reserve Bank of Dallas or the Federal Reserve System.
} 
In spite of the growing importance of emerging markets in the global economy and the increasing number of students from developing countries enrolled in U.S. universities, most of the macroeconomics textbooks that we use in class do not include a section dedicated to business cycles facts and microfounded models for emerging market and developing economies (EMDEs). Expositions of the frictionless business cycle model, such as the ones we find in Barro (1997), Jones (2013), and Williamson (2013), constitute a useful but insufficient starting point for a student who seeks to learn how aggregate fluctuations work in the developing world. The reason is simple: business cycles are different in EMDEs. Deeper recessions, larger swings of consumption relative to output, and countercyclical interest rates are just some of those regularities that cannot be explained well by standard textbooks.

In the emerging world, on the other hand, many instructors use either textbooks originally written by them or translated (occasionally adapted) versions of the textbooks used in industrialized economies. In any case, such teaching materials do not contain simple models that can account for the business cycle facts mentioned above. ${ }^{1}$ This becomes even more relevant when we consider that the larger the macroeconomic fluctuations, the larger the subsequent welfare costs. ${ }^{2}$

Authors interested in EMDEs are aware of the methodological importance of modern business cycles models but, perhaps surprisingly, have not yet taken a decisive step to include such material in their textbooks. De Gregorio (2012), former chairman of the Central Bank of Chile and author of an intermediate macroeconomics textbook used in several Latin American universities, illustrates this point:

"Therefore, we can affirm that, from a methodological point of view, the $R B C$ models have been successful, but its success is still doubtful in terms of describing what happens in reality. This is particularly relevant in emerging economies" (De Gregorio 2012, 661). 
Such skepticism about the usefulness of business cycle models, however, seems to be at odds with recent advances in this literature. During the last decade, useful dynamic stochastic equilibrium models for EMDEs have been proposed and confronted with actual data. Neumeyer and Perri (2005) and Aguiar and Gopinath (2007) are two key contributions that have, in turn, triggered numerous related works. Despite their ability to match several relevant facts, these models have not yet been incorporated to intermediate macroeconomics textbooks, perhaps due to their complexity.

In this paper, we try to fill this void by reformulating such models - AG model and NP model henceforth- in a simple setting that can be used by instructors to teach business cycle macroeconomics at undergraduate level. The setup is sufficiently simple that it can allow a nonspecialist or a policymaker to easily perform back-of-the-envelope analysis. The strategy is to formulate a two-period nonstochastic version of each model and, then, reduce the equilibrium conditions to a set of five equations and five key endogenous variables. Rather than modeling aggregates directly, we derive supply and demand relationships from first principles as in Barro (1997) or Williamson (2013) and end up with a two-graph model, which facilitates a straightforward learning of the transmission mechanisms.

The reformulated models are useful for understanding business cycle facts such as the following: (1) highly countercyclical trade balances, (2) the countercyclicality of the real interest rate, ${ }^{3}(3)$ the higher GDP and consumption volatility in EMDEs, and (4) the higher real wage volatility compared with developed economies. ${ }^{4}$ Simple extensions of the models can be used to understand other empirical facts that characterize the developing world such as capital outflows and crises, small government spending multipliers (Ilzetzki, Mendoza and Végh 2013), the cyclical behavior of prices, and the negative comovement between currency depreciations and output. Other applications are shown in the Appendix in the form of suggested exercises. It is important to underline that 
even though the models emphasize productivity shocks, we prefer to understand them in a wide sense as supply shocks, which can be capturing changes in either the relative price of imported inputs or institutional quality. ${ }^{5}$

The next section describes the AG model, its basic features, and main predictions. The third section carries out the same tasks for the NP model. The fourth section shows other applications and some extensions. The last section concludes with final remarks. The Appendix presents the mathematical formulations of the models (which are potentially useful material for an audience of upper-level undergraduate and graduate students) and a discussion of the limitations that other models, such as the traditional and a new version of the IS-LM-BP, have to account for the facts listed above.

\section{A SIMPLIFIED VERSION OF THE}

\section{AGUIAR-GOPINATH MODEL}

\section{The Original Model}

The model originally proposed by Aguiar and Gopinath (2007) is a dynamic stochastic equilibrium model. The economy is populated by identical consumers and identical firms with infinite lifetime. Given its nature, the model does not have an analytical solution and it is approximately solved through numerical methods. The model represents a single-good, single-asset small open economy (SOE) where the world real interest rate is given. The key feature that distinguishes this model from the canonical SOE model (e.g., Mendoza 1991) is that productivity shocks are assumed to be non-stationary in emerging economies (more on this below), whereas they are stationary in advanced countries. The authors provide empirical evidence that supports this model feature. The nonstationary 
feature implies that the long-run trend of productivity is changing stochastically over time, reflecting institutional changes and policy reversals (e.g., expropriations).

The AG model can account for (i) the strongly countercyclical nature of the trade balance for emerging markets compared with developed markets, (ii) the higher volatility of income in emerging markets, and (iii) the volatility of consumption compared with income volatility observed in emerging markets vis-à-vis developed markets.

\section{The Two-Period Version}

We reformulate the original model in three dimensions: economic agents live only two periods (present and future), the environment is deterministic, and we adopt GreenwoodHercowitz-Huffman (GHH) preferences to obtain a simple analytical solution and make it comparable to the NP model. ${ }^{6}$ The formulation and solution of the model is displayed in Appendix A.

The consumer chooses current and future consumption $\left(C, C^{\prime}\right)$, labor $\left(N^{s}, N^{s^{\prime}}\right)$, and the future stock of net assets $\left(B^{\prime}\right)$ to maximize an intertemporal utility subject to the corresponding budget constraints. The firm chooses current and future labor $\left(N^{d}, N^{d^{\prime}}\right)$ and future capital stock $\left(K^{\prime}\right)$ to maximize the present value of profits, given the available technology summarized by standard production functions $Y=z F\left(K, N^{d}\right)$ and $Y^{\prime}=$ $z^{\prime} F\left(K^{\prime}, N^{d^{\prime}}\right)$, where $z$ and $z^{\prime}$ are current and future total factor productivities (TFPs), and given the law of motion of capital: $K^{\prime}=(1-d) K+I$, where $I$ denotes investment and $d$ is the depreciation rate. Consumers and firms are price takers in the labor market, so they make optimal choices given current and future real wages $\left(w, w^{\prime}\right)$.

In this SOE model, the country real interest rate, $r$, depends entirely on the exogenous world real interest rate $r^{w}$. If we assume that the initial stock of assets is zero, $B=0$, the current account balance equals net exports. These, in turn, can be defined as the 
difference between current output and current domestic absorption (consumption and investment):

$$
N X=Y-(C+I)
$$

This implies that $N X$ adjusts endogenously whenever there is a change in the difference between current total output and current domestic absorption. Thus, the sign of the trade or current account surplus depends on such a difference.

The main endogenous variables are: $r, w, N^{s}, N^{d}, Y, C, K^{\prime}, I$, and $N X$ (net exports). The remaining endogenous variables are the future counterparts of the current variables listed before $\left(w^{\prime}, N^{s^{\prime}}\right.$, etc.; except $K^{\prime}, I$, and $\left.N X\right)$. The main exogenous variables are: $r^{w}, z, z^{\prime}, B$, and $K .^{7}$

\section{Simplified Version of the Model}

There are two alternative ways to present the simplified version of the model with the first-period variables. One possibility is to introduce the model using the corresponding supply-demand diagrams. The supply-demand diagram in the labor market allows us to determine the real wage and employment, whereas the supply-demand diagram in the goods market determines output and, implicitly, net exports at a given world interest rate. Alternatively, we can introduce the equations that summarize the equilibrium conditions and the country interest rate, and then show the corresponding graphical representation. This can be carried out with an explanation on how the relevant exogenous variables interact with the endogenous variables in both markets. 
The model, derived in Appendix A, can be summarized by the following five equations:

$$
\begin{aligned}
& N^{s}=w \\
& N^{d}=N^{d}(\underset{-}{w}, \underset{+}{z}, \underset{+}{K}) \\
& Y^{s}=z F(\underset{+}{K}, \underset{+}{N}) \\
& Y^{d}=C^{d}\left(\underset{-}{r}, \underset{+}{z}, z_{+}^{\prime}, K_{+}^{K}\right)+I^{d}\left(\underline{r}_{+}, z_{+}^{\prime}, K_{-}\right)+N X \\
& r=r^{w}
\end{aligned}
$$

A competitive equilibrium in this economy is a set of quantities and prices such that the consumer and the firm optimize subject to their corresponding constraints, and supply equals demand in the labor market and the goods market. ${ }^{8}$ Markets clear in the current period if

$$
\begin{aligned}
& N^{s}=N^{d} \\
& Y^{s}=Y^{d}
\end{aligned}
$$

Analogous market-clearing conditions hold for the second period.

Given the exogenous variables and the market-clearing conditions, expressions (1)-(5) constitute a system of equations that allows us to solve for $w, N, Y, r$ and $N X$. Other endogenous variables can be obtained from the solution of such a system. A plus or minus sign below an argument in a function represents the direction of influence of the right-hand-side variable on the left-hand-side variable. ${ }^{9}$

According to equation (1), the labor supply is a straight upward-sloping line on the $(N, w)$ plane (see its derivation in Appendix A). Consumers supply labor following an optimality rule that relates the real wage to the marginal rate of substitution (MRS) between leisure and consumption, which in this case depends only on work time and 
preference parameters. The adoption of GHH preferences makes the labor supply a function only of the real wage, independent of consumption. ${ }^{10}$

Equation (2) indicates that firms demand labor according to the marginal productivity rule (which depends on current total factor productivity), and the current stock of capital. An increase in either current total factor productivity or the current stock of capital raises the marginal product of labor and, therefore, the firm demands more work. Equation (3) implies that firms supply goods according to the production function, which is increasing in inputs (capital and labor) and TFP.

In equation (4), the current output demand is the sum of the current demand for consumption goods $\left(C^{d}\right)$, the current demand for investment goods $\left(I^{d}\right)$, and net exports because we have omitted a government sector (an assumption to be relaxed in the fourth section). If the substitution effect is greater than the income effect, consumption depends negatively on the real interest. ${ }^{11}$ On the other hand, an increase in either the current stock of capital, current TFP or future TFP raises lifetime wealth (the present value of income), and stimulates current consumption. Because $r$ is the opportunity cost of capital, investment also depends inversely on the interest rate. Future TFP also encourages firms to invest more in physical capital. A decrease in the current stock of capital also stimulates firms to invest more. ${ }^{12}$ Finally, the country interest rate is equal to the world interest rate by the no-arbitrage condition (5).

\section{Graphical Representation}

We can derive the output demand and output supply curves intuitively on the plane $(Y, r)$. Assume that, for some reason, there is an increase in the real interest rate. Current consumption and investment decline as borrowing becomes more expensive. ${ }^{13}$ As a result, the quantity of goods demanded falls. Thus, there is a negative relationship 
between the quantity demanded and the real interest rate. This is a standard result often found in a number of textbooks.

The output demand curve is downward sloping because two of its components, $C$ and $I$, depend negatively on the real interest rate. In contrast, the output supply curve is vertical because $z$ and $K$ are exogenous and $N$ does not depend on the real interest rate. The latter claim can be understood by examining equations (1) and (2), above.

The graphical representation of this model is given by the following supply-demand diagrams:
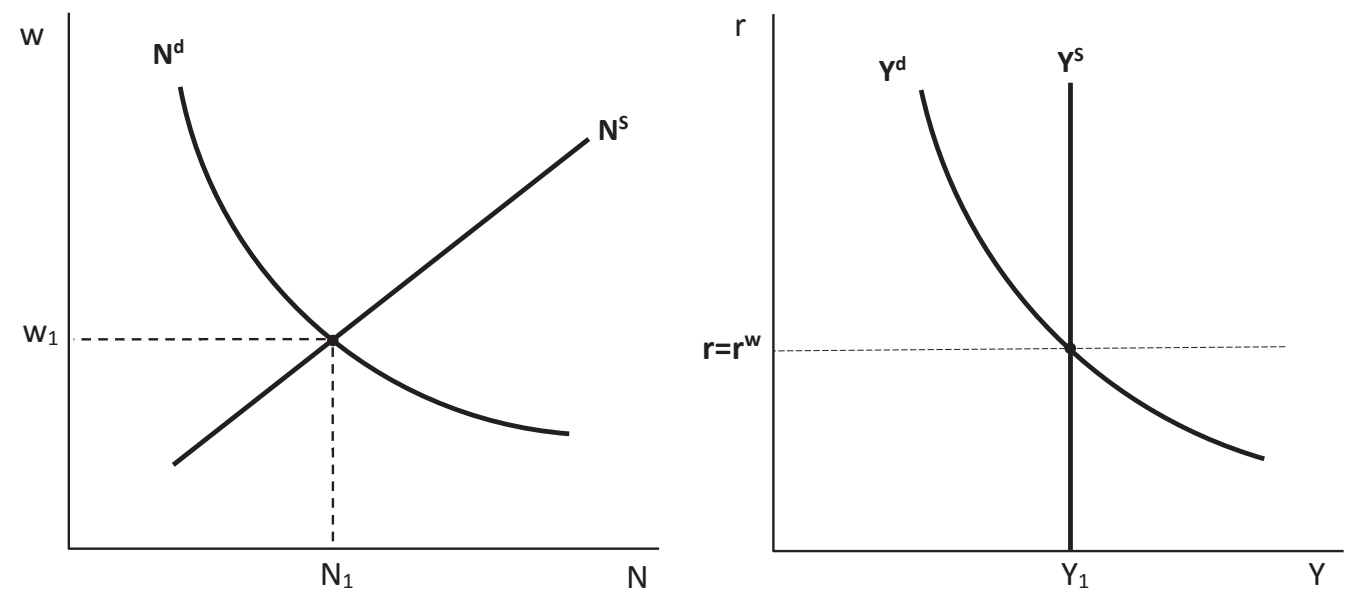

Figure 1: Equilibrium in the Aguiar-Gopinath model.

\section{Productivity Processes}

In this two-period deterministic setting, we model the nonstationary TFP changes in an analogous way. Assume that current and future TFP evolve as

$$
\begin{gathered}
z=z^{-}+\epsilon \\
z^{\prime}=z+\epsilon
\end{gathered}
$$


where $z^{-}>0$ is the level of TFP at the beginning of period 1, $\epsilon$ is a deterministic, exogenous drift component, and $\epsilon \in\left(-\frac{z^{-}}{2}, \frac{z^{-}}{2}\right)$.

Some comments are in order. First, note that the drift component $\epsilon$ affects $z$ directly (see expression (6)) and also $z^{\prime}$ indirectly via $z$ (see equation (7)). More importantly, the indirect effect is as strong as the direct effect. Because $\Delta z=\epsilon$, we have that $\Delta z^{\prime}=\epsilon$. In other words, a drift in the current level of TFP can have a permanent effect of the same size in future TFP. A shortcut to capture this feature is simply to say that $\Delta z^{\prime}=\Delta z$. Second, this model feature aims to capture what the authors call "the cycle is the trend". This is the most important difference with respect to the canonical SOE-RBC model, in which shocks are stationary and persistent effects are such that the change in future TFP is smaller than is the change in current TFP $\left(\Delta z^{\prime}<\Delta z\right) .{ }^{14}$ Third, these processes directly imply that output is more volatile in this model than in the canonical SOE-RBC model frequently used to analyze advanced countries.

\section{How Does the Model Work?}

\section{An Increase in Current and Future Total Factor Productivity}

Consider an exogenous increase in current and future $\operatorname{TFP}\left(\Delta z=\Delta z^{\prime}>0\right)$. We can decompose the analysis in three steps. First, the rise in current TFP expands the output supply (see equation (3)), and its vertical line shifts from $Y^{s}\left(z_{1}\right)$ to $Y^{s}\left(z_{2}\right)$. Second, the higher future TFP makes the output demand curve shift to the right, up to $Y^{d}\left(z_{2}^{\prime}, N X_{1}\right)$. This shift is greater than that of the output supply. The reason has to do with the TFP processes explained earlier. Although the output supply shifts because of the increase in $z$, the output demand shifts more not only due to the increase in $z$ but also because of the increase in $z^{\prime}$, which raises consumption and investment (see equation (4)). Third, at the real interest rate $r^{w}$, the quantity supplied is less than the quantity demanded 
for goods. Thus, imports must increase and net exports must decline to restore the equilibrium in the goods market. In other words, the output demand curve shifts back up to its intersection with the output supply curve $\left(Y^{d}\left(z_{2}^{\prime}, N X_{2}\right)\right)$ at the level $Y_{2}$. As a result, output increases $\left(Y_{1}<Y_{2}\right)$, whereas net exports diminish $\left(N X_{1}>N X_{2}\right)$. These effects lead to a negative comovement between GDP and the current account. If the economy is regularly hit by such persistent changes in productivity, then we should observe the countercylicality of the current account, as the EMDEs' data show.
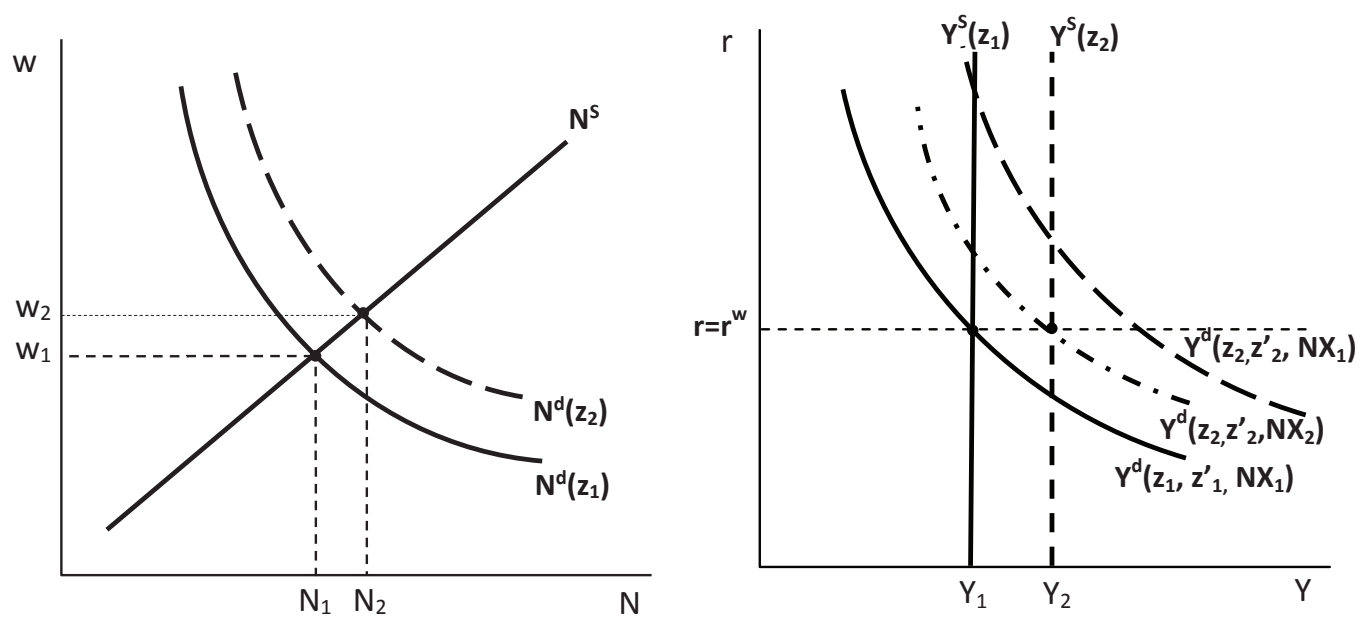

Figure 2: An increase in current and future TFP.

In the labor market, higher current productivity expands labor demand (by equation (2)) and, consequently, employment and the real wage increase as shown on the left side of Figure 2. Concerning consumption, this variable reacts strongly due to the significant increase in current and, particularly, future TFP, which in turn causes a significant increase in lifetime wealth. Consumption smoothing leads the individual to borrow against future income, generating a countercyclical behavior in the current account. Investment is also strongly encouraged by a higher future TFP. In sum, the model correctly predicts that the real wage, employment, consumption, and investment are procyclical, and the current account is countercyclical. 


\section{Advanced Small Open Economies}

How can we use this model to understand business cycles in an advanced SOE? For that purpose, we need to return to the processes that describe the TFP changes. In this case, the effect on current TFP is greater than the increase in future TFP $\left(\Delta z>\Delta z^{\prime}\right)$. Then, consumption, investment, and output demand do not increase as much as in the case described above. As a result, net exports decrease, but to a lesser degree than shown in Figure 2. That is, not only output but also consumption and investment are less volatile, and the trade balance is less countercyclical than in EMDEs. ${ }^{15}$

\section{A SIMPLIFIED VERSION OF THE NEUMEYER-PERRI MODEL}

\section{The Original Model}

There are three key differences with respect to the Aguiar and Gopinath (2007) model. First, firms face a working-capital requirement. A fraction of labor costs is financed at the real interest rate through an intraperiod bond. ${ }^{16}$ Second, the country real interest equals the world real interest rate plus a default premium that depends negatively on expected TFP. Third, TFP shocks are stationary.

The NP model can account for facts (i) through (iii) as mentioned in the second section, and (iv) the countercyclical behavior of the country real interest rate. ${ }^{17}$ Although this was not its original objective, we argue below that the model can also be used to explain the high volatility of the real wage observed in EMDEs. 


\section{The Two-Period Version}

The consumer's problem is essentially the same as in the AG model. In contrast, the firm's problem has a key difference. Profits include the cost of financing a fraction $(\theta)$ of labor $\operatorname{costs}(w N)$ due to the working-capital requirement in each period. This causes the labor demand to depend on the real interest rate and works as an amplifying mechanism of exogenous shocks in the interest rate.

The second key feature of the model is related to the country real interest rate. Domestic lenders always pay their debts completely, but there is a probability that the local government -not explicitly modeled here- will expropriate interests paid by local borrowers to foreign lenders. This implies that the domestic real interest rate responds directly to the world real interest rate and the country risk premium $p$. This, in turn, is endogenous to future TFP. Any increase in $z^{\prime}$-regarded as good news by international investors- reduces the country risk premium. In sum, $r=r^{w}+p\left(z_{-}^{\prime}\right)$. This constitutes a striking difference with respect to advanced economies because they mostly show acyclical country risk premia.

Third, we can assume that a persistent change in TFP implies $|\Delta z|>\left|\Delta z^{\prime}\right|$. It is useful to mention that a temporary change in TFP is represented by a change in $z$, an anticipated change in future TFP is represented by a change in $z^{\prime}$, and a persistent change in TFP is represented by a change in both $z$ and $z^{\prime}$ with $|\Delta z|>\left|\Delta z^{\prime}\right|$.

The formulation and solution of the model is displayed in Appendix B. The set of exogenous and endogenous variables is almost the same as the one in the AG model, except that we should add $p$ as an endogenous variable. A competitive equilibrium in this economy is a set of quantities and prices such that the consumer and the firm optimize subject to their corresponding constraints, and supply equals demand in the labor and the goods markets. 


\section{Simplified Version of the Model}

The model, derived in Appendix B, can be summarized by the following five equations:

$$
\begin{aligned}
& N^{s}=w \\
& N^{d}=N^{d}(\underset{+}{w, z}, \underset{+}{z}, \underset{-}{r}) \\
& Y^{s}=z F(K, N(r)) \\
& Y^{d}=C^{d}\left(\underset{-}{r}, \underset{+}{z}, z_{+}^{\prime}, K_{+}^{K}\right)+I^{d}\left(\underline{-}_{+}^{r}, z_{-}^{\prime}, K\right)+N X \\
& r=r^{w}+p\left(z_{-}^{\prime}\right)
\end{aligned}
$$

As before, given the exogenous variables and the market-clearing conditions, these five expressions constitute a system of equations that allows us to solve for $w, N, Y, r$ and $N X$.

Let us focus on the new equations. Equation (9) indicates that firms demand labor according to the marginal productivity rule, which depends on current TFP, the current stock of capital, and the real interest rate due to the working-capital assumption. An increase in the interest rate raises the cost of financing labor and, as a result, lowers labor demand.

Firms supply goods according to the production function (10). Note that we now include $N(r)$ with a negative sign because employment depends negatively on the interest rate, as explained above. Finally, the country interest rate is determined in the assets market by the no-arbitrage condition given by (12). Thus, persistent productivity fluctuations, defined as variations in current and future TFP, can cause a countercyclical real interest rate. 


\section{Graphical Representation}

The slopes of the labor demand, the labor supply, and the output demand are standard. However, the slope of the output supply curve is atypical. Imagine that, for some reason, the real interest rate increases. What is the effect on the quantity of goods supplied? Given the financial friction adopted, financing labor costs becomes more expensive and, consequently, the firm reduces its labor demand. The labor supply does not react to changes in the interest rate because GHH preferences do not allow any wealth effect. Therefore, employment falls and, consequently, the quantity of goods supplied falls as well. That is, there is a negative relationship between the quantity of goods supplied and the real interest rate. This is a key difference with respect to the upward-sloping supply curve of a frictionless model (see Williamson, 2013).

The graphical representation of this model is given by the following supply-demand diagrams:
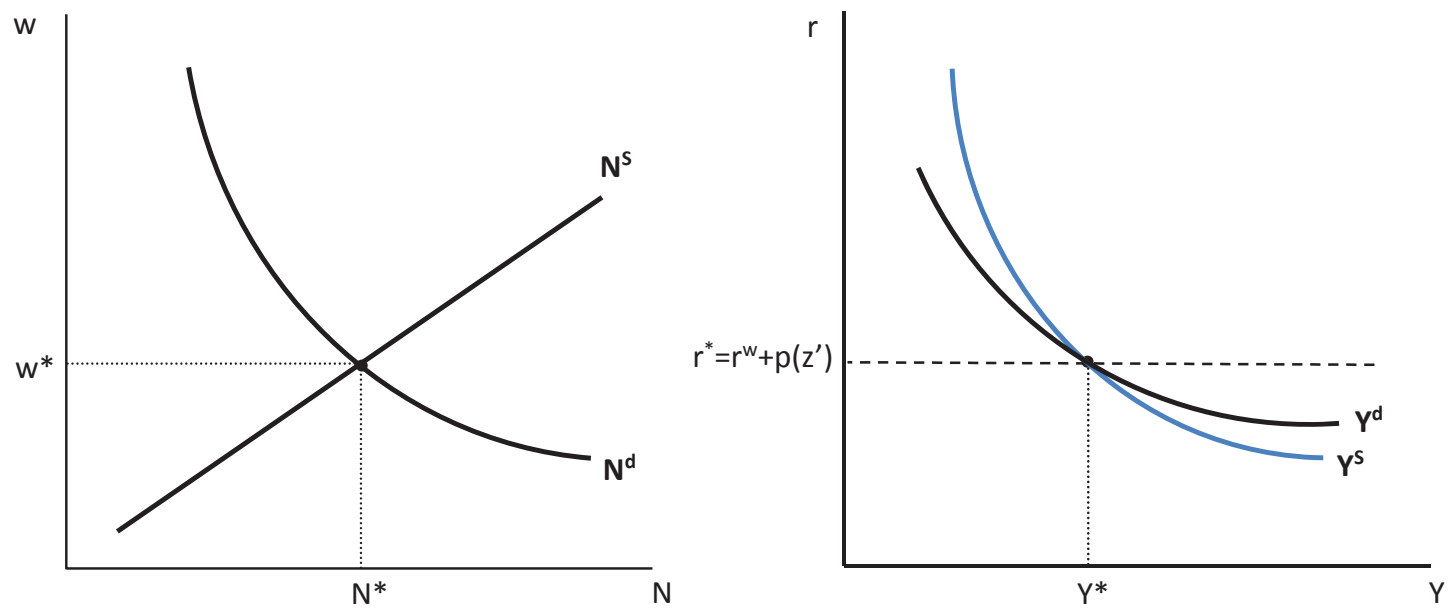

Figure 3: Equilibrium in the Neumeyer-Perri Model.

Two comments are worth mentioning here. First, note that the horizontal dashed line in the right-hand graph represents the domestic interest rate as the sum of the world interest and the country risk premium. Second, we assume that the working-capital 
friction is not sufficiently large to make the output demand steeper than the output supply. The flatter curve represents the output demand. Changes in the real interest rate affect the quantity demanded (consumption and investment) more than they affect the quantity supplied. ${ }^{18}$

\section{How Does the Model Work?}

It is useful to analyze separately the effects of a change in current TFP, a change in future TFP, and then the combination of both, that is, a persistent change in TFP.

\section{An Increase in Current Total Factor Productivity}

Let us initially consider a transitory increase in current TFP $\left(z_{1}<z_{2}\right)$ that expands the output supply due to a direct effect of $z$ and an indirect effect through a higher level of work, both in the production function (see equation (10)). This shift can be observed in Figure 4, which shows a new output supply $Y^{s}\left(z_{2}\right)$. At interest rate $r_{1}$, there is a gap between the quantity of goods supplied and the quantity of goods demanded. This requires an increase in net exports; the subsequent increase in the output demand and total output $\left(Y_{1}<Y_{2}\right)$ are shown below. ${ }^{19}$ 

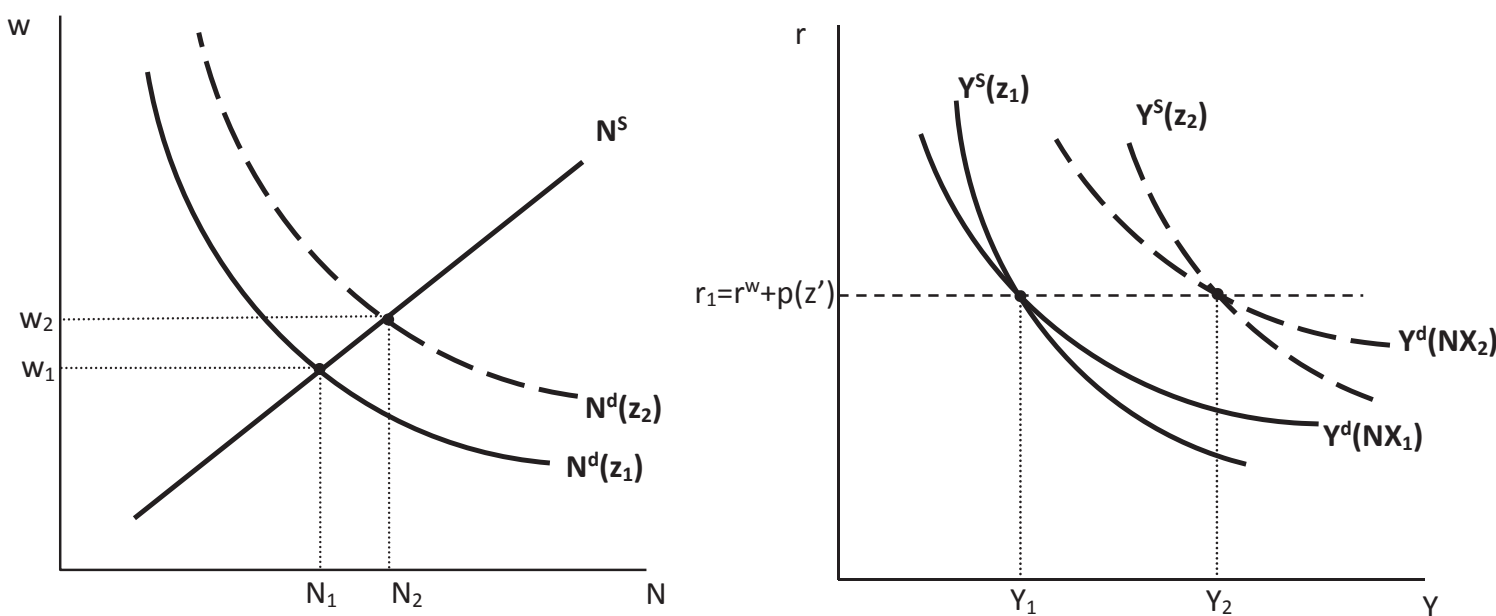

Figure 4: An increase in current total factor productivity.

Regarding the labor market, higher current TFP expands the labor demand (by equation (9)) and, as a result, raises employment and the real wage (see the left side of Figure $4)$.

\section{An Increase in Future Total Factor Productivity}

An anticipated increase in future TFP $\left(z_{1}^{\prime}<z_{2}^{\prime}\right)$ raises consumption and investment and expands output demand (by equation (11)). This is represented in Figure 5, on the right side, by the new output demand $Y^{d}\left(z_{2}^{\prime}, N X_{1}\right)$. The rise in future TFP lowers the country risk premium and, therefore, the country interest rate. At the new interest rate $r_{2}$, the quantity of goods supplied is lower than the quantity of goods demanded. Thus, net exports diminish and the output demand curve shifts back up to its intersection with the output supply curve at rate $r_{2}$. As a result, output increases $\left(Y_{1}<Y_{2}\right)$. 

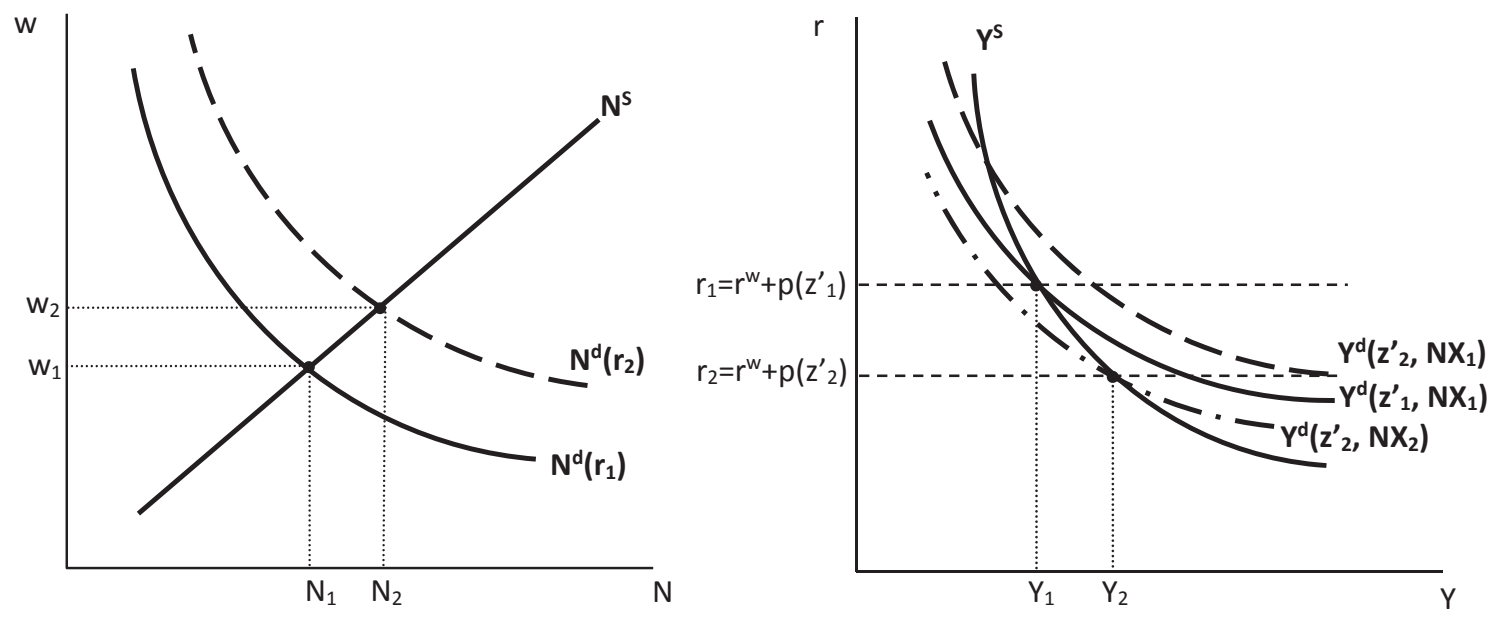

Figure 5: An increase in future total factor productivity.

Simultaneously, the lower interest rate expands labor demand and, consequently, employment and the real wage increase as shown on the left side of Figure 5.

\section{An Increase in Current and Future Total Factor Productivity}

A persistent productivity increase combines the increase in both current and future TFP, as discussed previously. First, the rise in current TFP expands the output supply and its curve shifts to $Y^{s}\left(z_{2}\right)$. Second, the higher future TFP makes the output demand shift to $Y^{d}\left(z_{2}^{\prime}, N X_{1}\right)$ and lowers the country risk premium so that the interest rate drops to $r_{2}$. Third, at the new interest rate, the quantity of goods supplied is lower than the quantity of goods demanded. Net exports fall to restore the equilibrium in the goods market, and the output demand curve shifts back up to its intersection with the output supply curve at rate $r_{2}$. As a result, output increases $\left(Y_{1}<Y_{2}\right)$, whereas net exports diminish $\left(N X_{1}>N X_{2}\right)$. This is the negative comovement between GDP and net exports. If the economy is regularly hit by persistent changes in productivity, then the NP model predicts the countercylicality of both the interest rate and the trade balance. In addition, we should observe an increase in both current consumption and investment. The lower real interest rate and the strong wealth effect, due to the increase in current and future 
TFP, stimulate consumption. Meanwhile, firms invest more because of the lower interest rate and the higher future TFP.
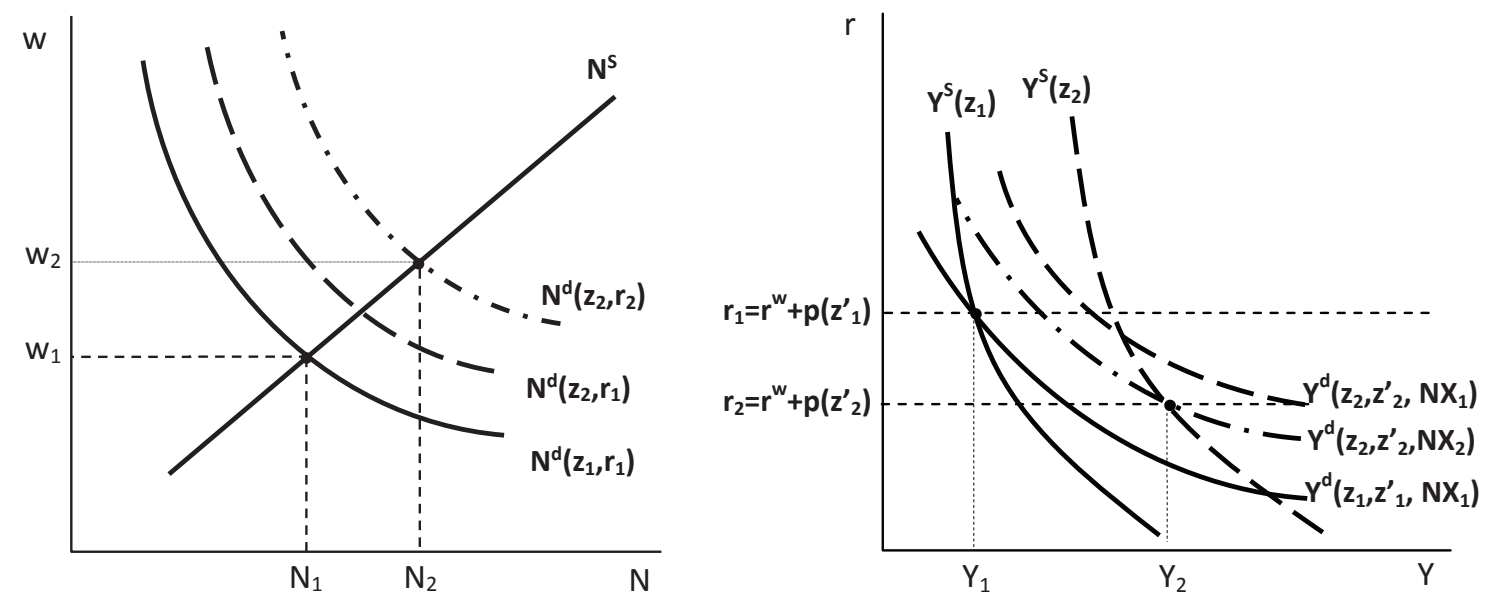

Figure 6: An increase in current and future total factor productivity.

In the labor market, the higher current productivity and the lower interest rate expand the labor demand and, consequently, employment and the real wage increase significantly, as shown on the left side of Figure 6. This figure also illustrates that real wage volatility is higher in emerging markets than in developed economies, as reported by Li (2011). If the default premium is virtually insensitive to TFP changes in a developed economy, then the effect of future TFP on the interest rate should be low or nil and, therefore, we should observe a small expansion, if any, of the labor demand. In summary, the model correctly predicts that the real wage, employment, consumption, and investment are procyclical, that the real interest rate and net exports are countercyclical and that the real wage is highly volatile.

\section{Why Is Consumption More Volatile in EMDEs?}

Consider two countries, an emerging or developing country and an advanced country with the same initial consumption level $C_{1}$ as shown in Figure 7 . Due to the presence of 
the financial friction described above, labor income is a function of the real interest rate, which makes current consumption more sensitive to changes in the real interest rate. ${ }^{20}$ Assuming that financial frictions are more important in an EMDE than in an advanced economy, the consumption curve on the $(C, r)$ plane is flatter for the EMD economy. That is, a given change in $r$ has a greater effect on $C^{E M D}$ than on $C^{A}$, as shown in Figure 7. Now, suppose that at the initial consumption level $C_{1}$ and interest rate $r_{1}$, there is a persistent increase in TFP that shifts both curves to the right. The acyclical nature of the risk premium in an advanced economy leaves its country interest rate at $r_{1}$ and consumption increases up to $C_{2}^{A}$. The EMDE, however, observes a reduction to $r_{2}$, and consumption can increase up to $C_{2}^{E M D}$, even more than in the advanced country. This turns consumption in an EMDE more volatile for a persistent TFP change of the same magnitude.

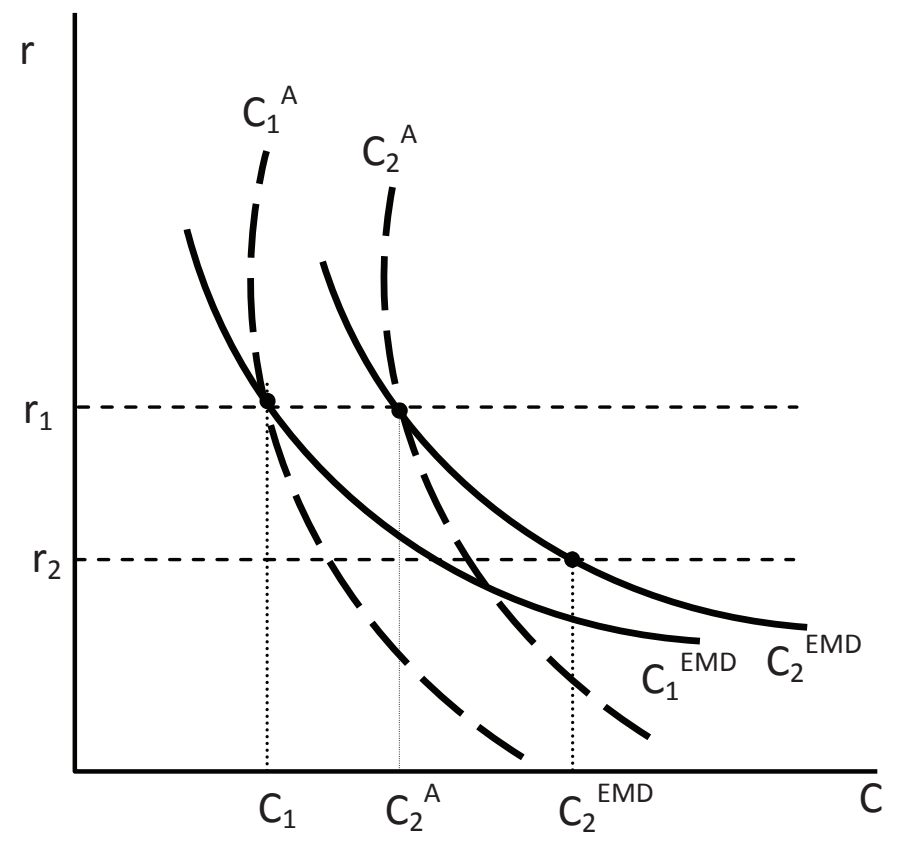

Figure 7: The effect of an increase in current and future TFP on current consumption. 


\section{OTHER APPLICATIONS AND EXTENSIONS}

Next we show other applications and simple extensions of the models. We give priority to simplicity and view these applications as complementary explanations to others given in the macroeconomic literature for EMDEs.

\section{Output Drops and Capital Outflows}

Some economists have observed that large reductions in the flow of international capital into an EMDE are accompanied by deep recessions. Kaminsky, Reinhart and Végh (2005) find that capital flows to EMDEs are procyclical. ${ }^{21}$ How can we understand a sharp capital outflow, its corresponding current account reversal, and an output drop in the NP model $?^{22}$ Consider an economy that experiences a persistent fall in TFP $\left(\Delta z<0, \Delta z^{\prime}<0,|\Delta z|>\left|\Delta z^{\prime}\right|\right)$. Based on our analysis in the third section, we can show that the effects on output and other endogenous variables have just the opposite signs that we see in Figure 6.

To see the effects on the current account more clearly, let us use an alternative diagram. We can express the current account surplus as the difference between national saving and investment: $C A=S-I$, where $S=Y-C$. Keeping in mind equations (10) and the current demand for consumption goods, we can formulate national saving as a function of the real interest rate, current and future TFPs, among other determinants. Recalling the expressions for the current demand for investment and the country interest rate (repeated here for convenience), we have:

$$
\begin{array}{r}
S=S\left(\underset{+}{r}, z, z_{-}^{\prime}, \ldots\right) \\
I=I\left(\underline{-}_{-}^{r}, z_{+}^{\prime}, \ldots\right) \\
r=r^{w}+p\left(z_{-}^{\prime}\right)
\end{array}
$$


These expressions are represented in Figure 8, which initially shows a current account deficit $\left(C A_{1}=S_{1}-I_{1}<0\right)$ at the real interest rate $r_{1}$. The persistent fall in TFP contracts both the saving curve and the investment curve, generating net capital outflows from the economy and a current account surplus. This surplus is enlarged by the jump in the real interest rate, which is a result of the rise in the country risk premium. At interest rate $r_{2}$, the current account surplus is positive and large $\left(C A_{2}=S_{2}-I_{2}>0\right)$.

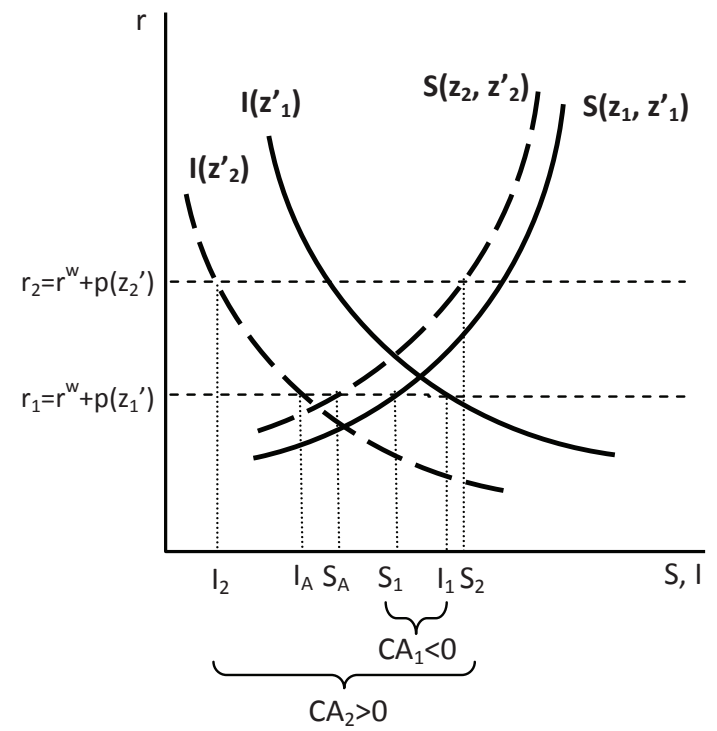

Figure 8: Output drops and capital outflows.

The graph is also useful to distinguish the effects of a persistent TFP reduction of the same magnitude on the current account of an advanced SOE and understand why current account balances are highly countercyclical in EMDEs. ${ }^{23}$ If the risk premium is not affected by future TFP in an advanced SOE, then there is no change in the country interest rate. At rate $r_{1}$, the saving and investment curves shift such that the economy runs a current account surplus given by $C A_{A}=S_{A}-I_{A}>0$. Thus, the graph shows that the current account surplus is larger in the EMDE than in the advanced SOE $\left(C A_{2}=S_{2}-I_{2}>S_{A}-I_{A}=C A_{A}\right)$. 


\section{The Small (Zero) Government Spending Multiplier}

Recently, Ilzetzki, Mendoza and Végh (2013) find that the government spending multiplier is statistically insignificant in EMDEs. ${ }^{24}$ One way to understand this finding is by adding a government sector in the NP model. Every period, the government purchases an amount of consumption goods that is fully financed by lump-sum taxes paid by consumers. That is, $G=T, G^{\prime}=T^{\prime}$, and, for simplicity, we omit government debt. ${ }^{25}$ This leads to a new equation for the current output demand:

$$
Y^{d}=C^{d}\left(\underline{r}, \underline{T}, T_{-}^{\prime}, \ldots\right)+I^{d}(\underline{r}, \ldots)+G+N X
$$

Consider now an increase in government spending financed with lump-sum taxes in the first period $(\Delta G=\Delta T>0)$. On the one hand, higher taxes reduce individuals' lifetime wealth, their current consumption and, as a result, output demand. On the other hand, the rise in public spending affects output demand directly and positively. Due to individuals' consumption-smoothing behavior, we expect that the negative effect on current consumption is smaller (in absolute value) than the positive effect of the increase in current public spending. As a result, the output demand increases. This effect is represented by an initial shift of the output demand curve to the right (up to $\left.Y^{d}\left(G_{2}, N X_{1}\right)\right)$ in Figure 9. Given that the quantity demanded exceeds the quantity supplied at interest rate $r_{1}$, the economy imports more goods and the trade balance deteriorates (net exports decline). This implies a full contraction of the output demand curve, back to the initial point with $Y^{d}\left(G_{2}, N X_{2}\right)$. In sum, there is a full crowding-out effect caused by higher imports. 


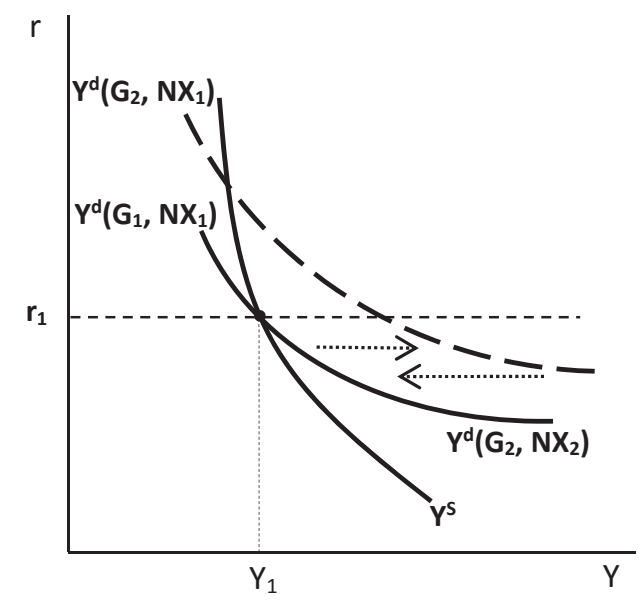

Figure 9: An increase in government spending.

\section{The Cyclical Behavior of Prices}

Rand and Tarp (2002) find that the cyclical component of the CPI is negatively correlated with (detrended) output in most developing countries. In other words, prices are countercyclical in EMDEs. ${ }^{26}$ Let us introduce a money market to the model using a similar approach as in Williamson (2013). For simplicity, the money supply $\left(M^{s}\right)$ is exogenously controlled by the central bank, and the money demand $\left(M^{d}\right)$ depends on total income and the interest rate as follows:

$$
\begin{array}{r}
M^{S}=M \\
\left.M^{d}=P L \underset{+}{P} \underset{-}{r}\right)
\end{array}
$$

where $P$ is the domestic price level determined in this market (see Figure 10). ${ }^{27}$ In Figure 10, we represent the money supply as a vertical line at the initial level $M_{1}$. The money demand is represented by the straight upward-sloping line $P=M / L(Y, r)$, with slope $1 / L(Y, r)$. 


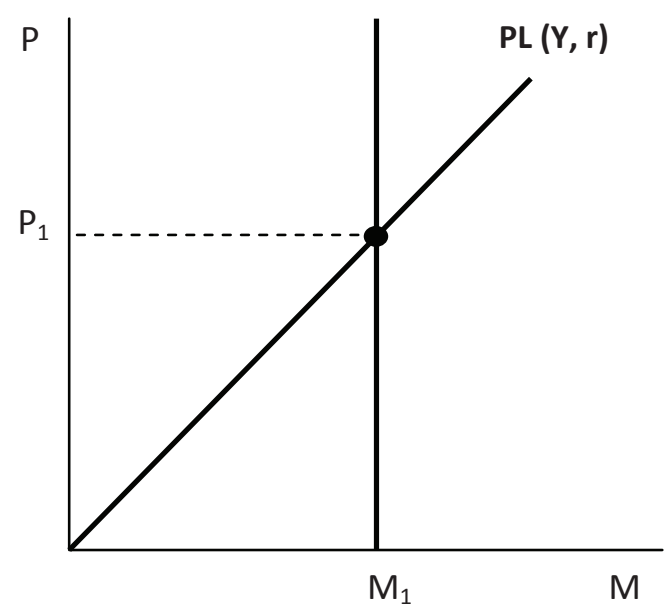

Figure 10: The equilibrium in the money market and the determination of the price level.

As previously shown, a persistent TFP increase raises income and lowers the interest rate. Unambiguously, money demand expands. This can be observed in Figure 11. Given a constant money supply, the subsequent excess demand at the initial price level $\left(P_{1}\right)$ is only satisfied by a fall in prices $\left(P_{1}>P_{2}\right)$. If the economy is systematically shocked by persistent TFP changes, this result yields to a negative comovement between output and prices. $^{28}$

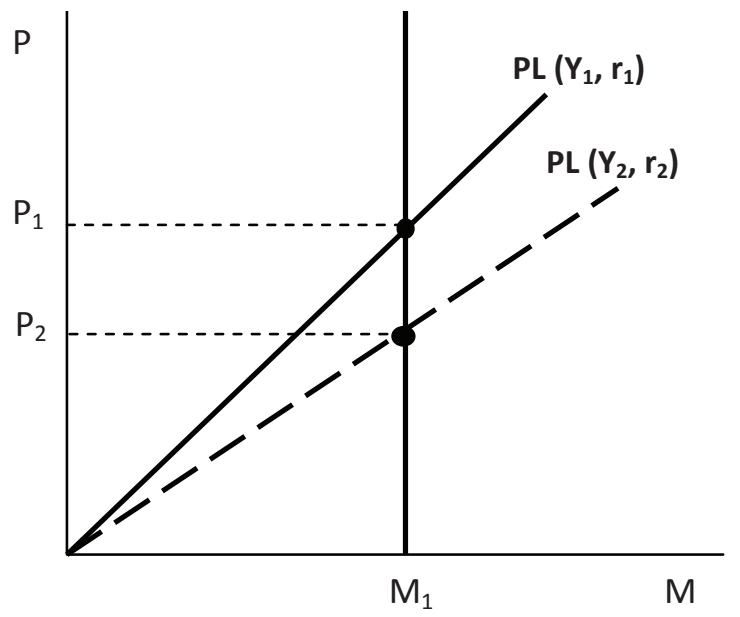

Figure 11: Countercyclical prices. 


\section{Currency Depreciations and Output}

Recent empirical evidence reported by Cordella and Gupta (2014) shows that currencies in EMDEs tend to depreciate when GDP growth is low and appreciate when GDP growth is high. That is, nominal exchange rates -defined as the relative price of a foreign currency in terms of the domestic currency- are countercyclical (currencies are procyclical) in most of the developing world. ${ }^{29}$ One possibility is that the nominal exchange rate is indirectly affected by output fluctuations, which in turn are caused by a third factor such as TFP changes. If this mechanism is empirically correct, then how can we explain the negative correlation between currency depreciations and output fluctuations using any of the models? Following Williamson (2013), assume that the purchasing power parity condition holds: ${ }^{30}$

$$
P=e P^{*}
$$

where $P^{*}$ is the foreign price level and $e$ is the nominal exchange rate defined such that an increase represents a depreciation of the domestic currency. If we plug equation (19) in (18), we obtain

$$
M^{d}=e P^{*} L(\underset{+}{Y}, \underset{-}{r})
$$

Equations (17) and (20) determine the nominal exchange rate in the money market under a flexible exchange rate regime. ${ }^{31}$ Figure 12 shows the interaction between supply and demand and the determination of the nominal exchange rate. 


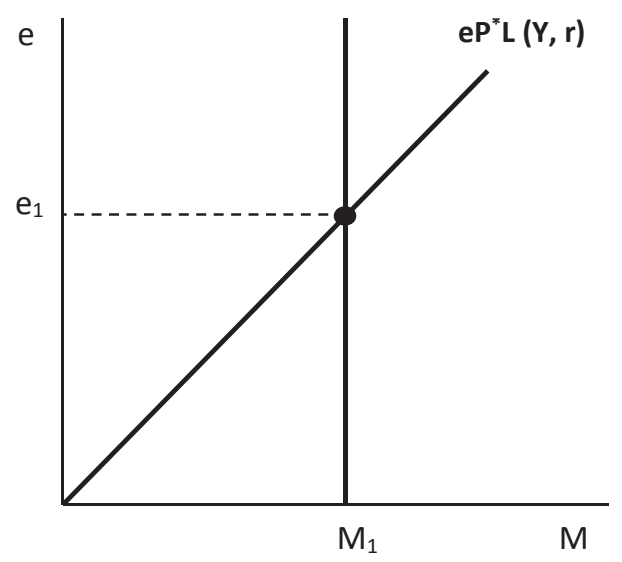

Figure 12: The money market and the determination of the nominal exchange rate.

Consider a persistent reduction in TFP that contracts output (in both models) and raises the interest rate (in the NP model). The reduced income leads to a lower demand for money and, as a result, a nominal depreciation of the currency (see Figure 13). Therefore, if the economy is regularly hit by persistent TFP changes, we should expect a negative comovement between the nominal exchange rate and output.

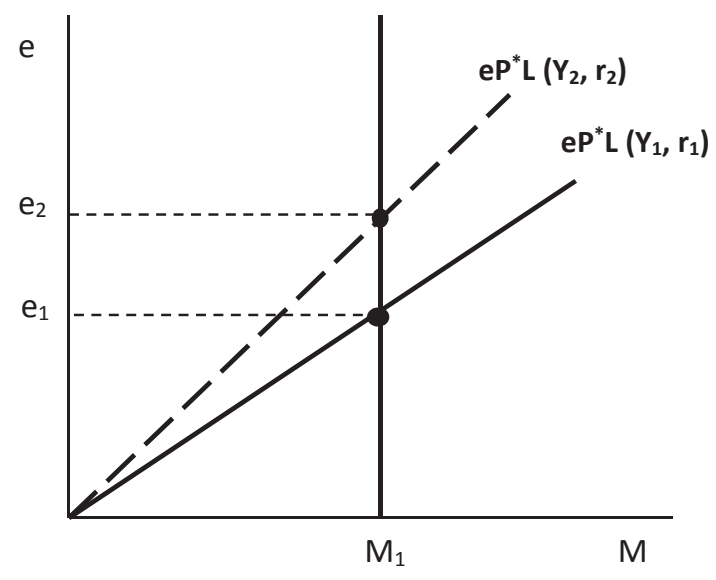

Figure 13: The negative comovement between the nominal exchange rate and output. 


\section{CONCLUDING REMARKS}

EMDEs not only differ from advanced economies in levels and growth rates of GDP but also in the volatility and comovement of the cyclical components of GDP and other macroeconomic variables. To understand business cycle facts in EMDEs more easily, we propose simplified versions of the original Aguiar-Gopinath and Neumeyer-Perri models and derive the equilibrium relationships of key macroeconomic variables such as output, the real wage, employment, and net exports. We show with a few diagrams that the models are useful to understand business cycle facts in EMDEs. These simple models could be taught not only in an intermediate macroeconomics course but also in courses of international finance or development economics. They also can be useful at the graduate level if the instructor needs to explain the economic intuition or address the two-period versions formulated in the Appendix. The main objective is that students, particularly from emerging market and developing countries, can learn these macroeconomic models to understand better how their own economies work.

The attentive reader most likely has noticed that we dedicate more pages to using and applying the NP model. One reason is that we can easily account for countercyclical interest rates and the higher volatility of the real wage. Another important reason to prefer the NP model is that, according to Chang and Fernández (2010), its original version shows a better data fit than does the original AG model. Indirect support is also given by Hevia (2014). The author concludes that models with financial frictions in the form of working capital constraints are consistent with empirical findings. García-Cicco, Pancrazzi and Uribe (2010) also find that permanent and transitory productivity shocks, as in the original AG model, cannot account properly for the business cycles observed in Argentina and Mexico, particularly the cyclical degree of their trade balances. That said, we find that the AG model could be more useful to understand fluctuations in developing economies that are mainly shocked by institutional changes and sharp policy reversals 
that affect their long-run trends. In that sense, we view both models as complementary tools.

It is worth mentioning that we do not suggest replacing or removing any model from the current textbooks but instead using the models proposed in this paper to complement the teaching toolbox and understand macroeconomic fluctuations in EMDEs. As discussed in the Appendix, the traditional IS-LM-BP and its version with balance-sheet effects are helpful to understand the role of exchange rates, monetary policy and amplification mechanisms. That being said, we believe that the NP and AG models perform very well in explaining business cycle facts in EMDEs. Perhaps it is time for an update and to include them in our classes. 


\section{REFERENCES}

Ahumada, I., and F. Butler. 2009. La enseñanza de la economía en México, InterAmerican Development Bank, Research Department Working Papers 672.

Aguiar, M., and G. Gopinath. 2007. Emerging Market Business Cycles: The Cycle is the Trend, Journal of Political Economy, 115(1).

Angelopoulos, K., G. Economides, and V. Vassilatos. 2011. Do institutions matter for economic fluctuations? Weak property rights in a business cycle model for Mexico, Review of Economic Dynamics, 14: 511-531.

Backus, D., and P. Kehoe. 1992. International Evidence on the Historical Properties of Business Cycles. American Economic Review 82(4): 864-888.

Barro, R. 1997. Macroeconomics. 5th edition, The MIT Press.

Boz, E., B. Durdu, and N. Li. 2012. Emerging Market Business Cycles: The Role of Labor Market Frictions, IMF Working Paper 237.

Calderón, C., and R. Duncan. 2003. Purchasing Power Parity in an Emerging Market Economy: A Long-span Study for Chile, Estudios de Economía, 30(1): 103-132.

Calderón, C., and J. R. Fuentes. 2014. Have business cycles changed over the last two decades? An empirical investigation, Journal of Development Economics 109: 98-123.

Calvo, G. 2003. Explaining Sudden Stop, Growth Collapse, and BOP Crisis: The Case of Distortionary Output Taxes, IMF Staff Papers 50: 1-20.

Castillo, P., C. Montoro, and V. Tuesta. 2007. Hechos estilizados de la economía peruana, Revista Estudios Económicos, 14: 33-75. 
Céspedes, L., R. Chang, and A. Velasco. 2003. IS-LM-BP in the Pampas. IMF Staff Papers 50: 143-156.

Céspedes, L., and R. Chang. 2007. Country Risk, Exchange Rates and Economic Fluctuations in Emerging Economies. Rutgers University, manuscript.

Chang, R., and A. Fernández. 2010. On the Sources of Aggregate Fluctuations in Emerging Economies. NBER Working Paper No. 15938.

Cordella, T., and P. Gupta. 2014. What Makes a Currency Procyclical? An Empirical Investigation. World Bank Policy Research Working Paper 7113.

De Gregorio, J. 2012. Macroeconomía: Teoría y Politicas. Pearson-Prentice Hall.

Duncan, R. 2014. Institutional Quality, the Cyclicality of Monetary Policy and Macroeconomic Volatility, Journal of Macroeconomics 39: 113-155.

Fernández-Villaverde, J., P. Quintana, J. Ramírez, and M. Uribe. 2011. Risk Matters: The Real Effects of Volatility Shocks, American Economic Review 101(6): 2530-2561.

García-Cicco, J., R. Pancrazzi, and M. Uribe. 2010. Real business cycles in emerging countries? American Economic Review, 100: 2510-2531.

Greenwood, J., Z. Hercowitz, and G. Huffman. 1988. Investment, capacity utilization and the real business cycle. American Economic Review 78, 402-417.

Hevia, C. 2014. Emerging market fluctuations: What makes the difference? Journal of International Economics 94(1): 33-49.

Ilzetzki, E., E. Mendoza, C. Végh. 2013. How big(small?) are fiscal multipliers? Journal of Monetary Economics 60: 239-254. 
Ilzetzki, E., C. Reinhart, K. Rogoff. 2009. Exchange Rate Arrangements Entering the 21st Century: Which Anchor Will Hold?, manuscript, Harvard University.

Jones, C. 2013. Macroeconomics. 3rd edition, W. W. Norton \& Company.

Kaminsky, G., C. Reinhart, C. Végh. 2005. When It Rains, It Pours: Procyclical Capital Flows and Macroeconomic Policies, in: Gertler, M., Rogoff, K (Eds.), NBER Macroeconomics Annual, Cambridge, MA, MIT Press.

Kim, Y., and Y. Ying. 2007. An empirical assessment of currency devaluation in East Asian countries, Journal of International Money and Finance 26:265-283.

Kraay, A. 2012. How large is the government spending multiplier? Evidence from World Bank lending, The Quarterly Journal of Economics 127: 829-887.

Kraay, A. 2014. Government Spending Multipliers in Developing Countries. Evidence from Lending by Official Creditors. American Economic Journal: Macroeconomics 6(4): $170-208$.

Li, N. 2011. Cyclical wage movements in emerging markets compared to developed economies: The role of interest rates, Review of Economic Dynamics 14: 686-704.

Lora, E., and H. Nopo. 2009. La formación de los economistas en América Latina, Inter-American Development Bank Working Paper 119.

Mankiw, G. 2013. Macroeconomía. Antoni Bosch Editor, 4th edition.

Mendoza, E. 1991. Real Business Cycles in a Small Open Economy, American Economic Review 81(4), 797-818. 
Montiel, P. 2011. Macroeconomics in emerging markets, Cambridge University Press, Second Edition.

Neumeyer, A., and F. Perri. 2005. Business Cycles in Emerging Economies: The Role of Interest Rates, Journal of Monetary Economics 52(2): 345-380.

Otsu, K. 2008. A neoclassical analysis of the Korean crisis, Review of Economic Dynamics 11: 449-471.

Oviedo, P. 2005. World Interest Rate, Business Cycles, and Financial Intermediation in Small Open Economies, manuscript, Iowa State University.

Pallage, S., and M. Robe. 2003. On the welfare cost of economic fluctuations in developing countries, International Economic Review 44(2): 677-698.

Raddatz, C. 2007. Are external shocks responsible for the instability of output in lowincome countries?, Journal of Development Economics 84: 155-187.

Rand, J., and F. Tarp. 2002. Business cycles in developing countries: are they different?, World Development 30: 2071-2088.

Sachs, J., and F. Larraín. 2002. Macroeconomía en la Economía Global. 2nd edition, Prentice-Hall.

Taylor, A. 2002. A Century of Purchasing-Power Parity, The Review of Economics and Statistics, 84 (1): 139-150.

Uribe, M., and S. Schmitt-Grohé. 2014. Open Economy Macroeconomics, Columbia University, manuscript. 
Uribe, M., and V. Yue. 2006. Country Spreads and Emerging Countries: Who Drives Whom?, Journal of International Economics 69: 6-36.

Williamson, S. 2013. Macroeconomics. 5th edition, Addison Wesley. 


\section{APPENDIX}

\section{The Two-Period AG Model}

\section{The consumers}

The consumer's problem consists of choosing $C, C^{\prime}, N, N^{\prime}$ and $B^{\prime}$ to: ${ }^{32}$

$$
\max \ln \left(C-\frac{N^{2}}{2}\right)+\beta \ln \left(C^{\prime}-\frac{N^{\prime 2}}{2}\right)
$$

s.t.:

$$
\begin{gathered}
C+B^{\prime}=w N+\pi \\
C^{\prime}=w^{\prime} N^{\prime}+\pi^{\prime}+(1+r) B^{\prime}
\end{gathered}
$$

where the initial stock of net assets $(B)$ is given, we assume $B=0$, and the transversality condition $B^{\prime \prime}=0$.

The Lagrangean function is

$\mathcal{L}=\ln \left(C-\frac{N^{2}}{2}\right)+\beta \ln \left(C^{\prime}-\frac{N^{\prime 2}}{2}\right)+\lambda\left[w N+\pi-C-B^{\prime}\right]+\lambda^{\prime}\left[w^{\prime} N^{\prime}+\pi+(1+r) B^{\prime}-C^{\prime}\right]$ 
The first-order conditions (FOCs) are

$$
\begin{aligned}
\frac{\partial \mathcal{L}}{\partial C}=\frac{1}{C-\frac{N^{2}}{2}}-\lambda & =0 \\
\frac{\partial \mathcal{L}}{\partial C^{\prime}}=\frac{\beta}{C^{\prime}-\frac{N^{\prime 2}}{2}}-\lambda^{\prime} & =0 \\
\frac{\partial \mathcal{L}}{\partial N}=-\frac{N}{C-\frac{N^{2}}{2}}+\lambda w & =0 \\
\frac{\partial \mathcal{L}}{\partial N^{\prime}}=-\frac{N^{\prime}}{C^{\prime}-\frac{N^{\prime 2}}{2}}+\lambda^{\prime} w^{\prime} & =0 \\
\frac{\partial \mathcal{L}}{\partial B^{\prime}}=-\lambda+\lambda^{\prime}(1+r) & =0 \\
\frac{\partial \mathcal{L}}{\partial \lambda}=w N+\pi-C-B^{\prime} & =0 \\
\frac{\partial \mathcal{L}}{\partial \lambda^{\prime}}=w^{\prime} N^{\prime}+\pi^{\prime}+(1+r) B^{\prime}-C^{\prime} & =0
\end{aligned}
$$

\section{The firms}

Assuming a Cobb-Douglas production function, the firm's current and future profits $\left(\pi, \pi^{\prime}\right)$ are

$$
\begin{array}{r}
\pi=z K^{\alpha} N^{1-\alpha}-w N-\left[K^{\prime}-(1-\delta) K\right] \\
\pi^{\prime}=z^{\prime} K^{\prime \alpha} N^{\prime 1-\alpha}-w^{\prime} N^{\prime}+(1-\delta) K^{\prime}
\end{array}
$$

where $0<\alpha<1$ is the capital share, $0<\delta<1$ is the depreciation rate, and we impose the transversality condition $K^{\prime \prime}=0$. Given the initial stock of capital $(K)$, the firm's problem consists of choosing $N, N^{\prime}$, and $K^{\prime}$ to maximize its value (the present value of profits, $V)$. That is,

$$
\max _{N, N^{\prime} K^{\prime}} \quad V=\pi+\frac{\pi^{\prime}}{1+r}
$$


The FOCs are

$$
\begin{aligned}
\frac{\partial V}{\partial N}=(1-\alpha) z K^{\alpha} N^{-\alpha}-w & =0 \\
\frac{\partial V}{\partial N^{\prime}}=(1-\alpha) z^{\prime} K^{\prime \alpha} N^{\prime-\alpha}-w^{\prime} & =0 \\
\frac{\partial V}{\partial K^{\prime}}=-1+\frac{\alpha z^{\prime} K^{\prime \alpha-1} N^{\prime-\alpha}+(1-\delta)}{1+r} & =0
\end{aligned}
$$

\section{Market-clearing conditions}

Markets clear in the present and future period if

$$
\begin{gathered}
N^{s}=N^{d} \\
N^{s^{\prime}}=N^{d^{\prime}} \\
Y^{s}=Y^{d} \\
Y^{s^{\prime}}=Y^{d^{\prime}}
\end{gathered}
$$

\section{Solution}

Given that $r=r^{w}$, the solution of the model is

$$
\begin{gathered}
N^{*}=w^{*}=\left[(1-\alpha) z K^{\alpha}\right]^{\frac{1}{1+\alpha}} \\
Y^{*}=z K^{\alpha}\left[(1-\alpha) z K^{\alpha}\right]^{\frac{1-\alpha}{1+\alpha}} \\
K^{*}=\left(\frac{\alpha z^{\prime}}{r+\delta}\right)^{\frac{1+\alpha}{1-\alpha}}(1-\alpha) z^{\prime}
\end{gathered}
$$




$$
\begin{gathered}
I^{*}=K^{\prime *}-(1-\delta) K \\
N^{\prime *}=w^{\prime *}=(1-\alpha) z^{\prime}\left(\frac{\alpha z^{\prime}}{r+\delta}\right)^{\frac{\alpha}{1-\alpha}} \\
Y^{\prime *}=z^{\prime} K^{\prime * \alpha} N^{\prime * 1-\alpha} \\
C^{*}=\frac{1}{(1+\beta)(1+r)}\left[\frac{\left(N^{\prime *}\right)^{2}}{2}\right]+\frac{1}{(1+\beta)}\left(\alpha Y^{*}+(1-\delta) K\right)+\frac{2+\beta}{1+\beta}\left[\frac{\left(N^{*}\right)^{2}}{2}\right] \\
N X^{*}=Y^{*}-C^{*}-I^{*} \\
C^{\prime *}=\frac{1+2 \beta}{1+\beta}\left[\frac{\left(N^{\prime *}\right)^{2}}{2}\right]+\frac{\beta(1+r)\left(\alpha Y^{*}+(1-\delta) K\right)}{1+\beta}+\frac{\beta(1+r)}{1+\beta}\left[\frac{\left(N^{*}\right)^{2}}{2}\right]
\end{gathered}
$$

\section{Supply and demand functions}

Using equations (21) and (23), we can derive the current labor supply

$$
N^{s}=w
$$

Equation (30) yields the current labor demand

$$
N^{d}=\left[\frac{(1-\alpha) z K^{\alpha}}{w}\right]^{\frac{1}{1-\alpha}}
$$


It is easy to prove that $\partial N^{d} / \partial z>0, \partial N^{d} / \partial K>0, \partial N^{d} / \partial w<0$. Recall that the current production function does not depend on the real interest and constitutes the current output supply:

$$
Y^{s}=z F(K, N)=z K^{\alpha} N^{1-\alpha}
$$

where, by assumption, $\partial Y^{s} / \partial z>0, \partial Y^{s} / \partial K>0$, and $\partial Y^{s} / \partial N>0$. The equations for the current demand for consumption goods, the future capital stock, and the current demand for investment goods $(43,39,40)$ yield

$$
\begin{gathered}
C^{d}=\frac{1}{(1+\beta)(1+r)}\left[\frac{\left(N^{*}\right)^{2}}{2}\right]+\frac{1}{(1+\beta)}\left(\alpha Y^{*}+(1-\delta) K\right)+\frac{2+\beta}{1+\beta}\left[\frac{\left(N^{*}\right)^{2}}{2}\right] \\
I^{d}=\left(\frac{\alpha z^{\prime}}{r+\delta}\right)^{\frac{1+\alpha}{1-\alpha}}(1-\alpha) z^{\prime}-(1-\delta) K
\end{gathered}
$$

It is straightforward to prove that $\partial C^{d} / \partial z>0, \partial C^{d} / \partial z^{\prime}>0, \partial C^{d} / \partial r<0, \partial C^{d} / \partial K>$ $0, \partial I^{d} / \partial z^{\prime}>0, \partial I^{d} / \partial r<0$, and $\partial I^{d} / \partial K<0$. Putting all of these elements together we have

$$
Y^{d}=C^{d}\left(\underset{-}{r}, \underset{+}{z}, z_{+}^{\prime}, \underset{+}{K}\right)+I^{d}\left(\underset{-}{r}, \underset{+}{z^{\prime}}, \underset{-}{K}\right)+N X
$$

Finally, rewriting equations (47)-(50) in general form, jointly with the parity of interest rates, we have the equations shown in the second section:

$$
\begin{gathered}
N^{s}=w \\
N^{d}=N^{d}\left(\underset{+}{w} \underset{+}{z, K_{+}}\right) \\
Y^{s}=z F\left(\underset{+}{K, N_{+}}\right)
\end{gathered}
$$




$$
\begin{aligned}
& Y^{d}=C^{d}\left(\underset{-}{r}, \underset{+}{z}, z_{+}^{\prime}, K_{+}\right)+I^{d}\left(\underline{r}_{+}, z_{+}^{\prime}, K\right)+N X \\
& r=r^{w}
\end{aligned}
$$

\section{The Two-Period NP Model}

This model is similar to the AG model described above, so we use similar definitions and notation and omit some equations shown previously.

\section{The consumers}

The consumer's problem is the same as the one formulated in the AG model. For convenience, we repeat the FOCs here.

$$
\begin{array}{r}
\frac{\partial \mathcal{L}}{\partial C}=\frac{1}{C-\frac{N^{2}}{2}}-\lambda=0 \\
\frac{\partial \mathcal{L}}{\partial C^{\prime}}=\frac{\beta}{C^{\prime}-\frac{N^{\prime 2}}{2}}-\lambda^{\prime}=0 \\
\frac{\partial \mathcal{L}}{\partial N}=-\frac{N}{C-\frac{N^{2}}{2}}+\lambda w=0 \\
\frac{\partial \mathcal{L}}{\partial N^{\prime}}=-\frac{N}{C^{\prime}-\frac{N^{\prime 2}}{2}}+\lambda^{\prime} w^{\prime}=0 \\
\frac{\partial \mathcal{L}}{\partial B^{\prime}}=-\lambda+\lambda^{\prime}(1+r)=0 \\
\frac{\partial \mathcal{L}}{\partial \lambda}=w N+\pi-C-B^{\prime}=0 \\
\frac{\partial \mathcal{L}}{\partial \lambda^{\prime}}=w^{\prime} N^{\prime}+\pi^{\prime}+(1+r) B^{\prime}-C^{\prime}=0
\end{array}
$$

\section{The firms}

The firm's problem is slightly different from the AG model's. We need to include the working capital requirement. Every period, the firm needs to finance a fraction $(\theta)$ of 
the labor costs at interest rate $r$. Thus, current and future profits are

$$
\begin{gathered}
\pi=z K^{\alpha} N^{1-\alpha}-w N-r \theta w N-\left[K^{\prime}-(1-\delta) K\right] \\
\pi^{\prime}=z^{\prime} K^{\prime \alpha} N^{\prime 1-\alpha}-w^{\prime} N^{\prime}-r^{\prime} \theta w^{\prime} N^{\prime}+(1-\delta) K^{\prime}
\end{gathered}
$$

Given the initial stock of capital $(K)$, the firm's problem consists of choosing $N, N^{\prime}$, and $K^{\prime}$ to maximize its value (the present value of profits, $V$ ):

$$
\max _{N, N^{\prime} K^{\prime}} \quad V=\pi+\frac{\pi^{\prime}}{1+r}
$$

The FOCs are

$$
\begin{aligned}
\frac{\partial V}{\partial N}=(1-\alpha) z K^{\alpha} N^{-\alpha}-(1+\theta r) w & =0 \\
\frac{\partial V}{\partial N^{\prime}}=(1-\alpha) z^{\prime} K^{\prime \alpha} N^{\prime-\alpha}-\left(1+\theta r^{\prime}\right) w^{\prime} & =0 \\
\frac{\partial V}{\partial K^{\prime}}=-1+\frac{\alpha z^{\prime} K^{\prime \alpha-1} N^{\prime 1-\alpha}+(1-\delta)}{1+r} & =0
\end{aligned}
$$

To simplify the analysis and without loss of generality, we assume that the exogenous components $r^{w}$ and $p\left(z^{\prime}\right)$ are such that $r=r^{\prime}$.

\section{Solution}

Given that $r=r^{w}+p\left(z^{\prime}\right)$, the solution of the model is

$$
\begin{aligned}
& N^{*}=w^{*}=\left[\frac{(1-\alpha) z K^{\alpha}}{1+\theta r}\right]^{\frac{1}{1+\alpha}} \\
& Y^{*}=z K^{\alpha}\left[\frac{(1-\alpha) z K^{\alpha}}{1+\theta r}\right]^{\frac{1-\alpha}{1+\alpha}}
\end{aligned}
$$




$$
\begin{aligned}
& K^{* *}=\left(\frac{\alpha z}{r+\delta}\right)^{\frac{1+\alpha}{1-\alpha}} \frac{(1-\alpha) z^{\prime}}{1+\theta r} \\
& I^{*}=K^{*}-(1-\delta) K \\
& N^{* *}=w^{*}=\frac{(1-\alpha) z^{\prime}}{1+\theta r}\left(\frac{\alpha z^{\prime}}{r+\delta}\right)^{\frac{\alpha}{1-\alpha}} \\
& Y^{\prime *}=z^{\prime} K^{\prime * \alpha} N^{\prime * 1-\alpha} \\
& C^{*}=\frac{1}{(1+\beta)(1+r)}\left[\frac{\left(N^{*}\right)^{2}}{2}\right]+\frac{1}{(1+\beta)}\left(\alpha Y^{*}+(1-\delta) K\right)+\frac{2+\beta}{1+\beta}\left[\frac{\left(N^{*}\right)^{2}}{2}\right] \\
& N X^{*}=Y^{*}-C^{*}-I^{*} \\
& B^{* *}=\theta r w^{*} N^{*}+N X^{*} \\
& C^{\prime *}=\frac{1+2 \beta}{1+\beta}\left[\frac{\left(N^{\prime *}\right)^{2}}{2}\right]+\frac{\beta(1+r)\left(\alpha Y^{*}+(1-\delta) K\right)}{1+\beta}+\frac{\beta(1+r)}{1+\beta}\left[\frac{\left(N^{*}\right)^{2}}{2}\right]
\end{aligned}
$$

\section{Supply and demand functions}

Using equations (51) and (53) we derive the current labor supply

$$
N^{s}=w
$$


Equation (60) yields the current labor demand

$$
N^{d}=\left[\frac{(1-\alpha) z K^{\alpha}}{(1+\theta r) w}\right]^{\frac{1}{1-\alpha}}
$$

It easy to prove that $\partial N^{d} / \partial z>0, \partial N^{d} / \partial K>0, \partial N^{d} / \partial w<0$, and $\partial N^{d} / \partial r<0$. Recall that the current production function does not depend on the real interest and constitutes the current output supply:

$$
Y^{s}=z F(K, N(r))=z K^{\alpha} N(r)^{1-\alpha}
$$

where, by assumption, $\partial Y^{s} / \partial z>0, \partial Y^{s} / \partial K>0$, and $\partial Y^{s} / \partial r<0$ because $\partial N / \partial r<0$. Equations for the current demand for consumption goods, the future capital stock, and the current demand for investment goods $(69,65,66)$ yield

$$
\begin{gathered}
C^{d}=\frac{1}{(1+\beta)(1+r)}\left[\frac{\left(N^{*}\right)^{2}}{2}\right]+\frac{1}{(1+\beta)}\left(\alpha Y^{*}+(1-\delta) K\right)+\frac{2+\beta}{1+\beta}\left[\frac{\left(N^{*}\right)^{2}}{2}\right] \\
I^{d}=\left(\frac{\alpha z}{r+\delta}\right)^{\frac{1+\alpha}{1-\alpha}} \frac{(1-\alpha) z^{\prime}}{1+\theta r}-(1-\delta) K
\end{gathered}
$$

It is straightforward to prove that $\partial C^{d} / \partial z>0, \partial C^{d} / \partial z^{\prime}>0, \partial C^{d} / \partial r<0, \partial C^{d} / \partial K>$ $0, \partial I^{d} / \partial z^{\prime}>0, \partial I^{d} / \partial r<0$, and $\partial I^{d} / \partial K<0$. Putting these elements together, we have

$$
Y^{d}=C^{d}\left(\underset{-}{r}, \underset{+}{z}, z_{+}^{\prime}, \underset{+}{K}\right)+I^{d}\left(\underset{-}{r} \underset{+}{z_{+}^{\prime}}, \underset{-}{K}\right)+N X
$$


Finally, rewriting equations (73)-(76) in general form, jointly with the parity of interest rates, we have the equations shown in the third section:

$$
\begin{aligned}
& N^{s}=w \\
& N^{d}=N^{d}(\underline{w}, \underset{+}{z}, \underline{K}, \underline{r}) \\
& Y^{s}=z F(K, N(r)) \\
& Y^{d}=C^{d}\left(\underline{-}_{-}^{z}, \underline{+}_{+}^{\prime},{ }_{+}^{K}\right)+I^{d}\left(\underline{-}_{+}^{z_{+}^{\prime}}, \underline{-}_{-}\right)+N X \\
& r=r^{w}+p\left(z^{\prime}\right)
\end{aligned}
$$

\section{Other Models}

How well do other models match EMDEs' business cycle facts? Let us discuss briefly the ability of the Mundell-Fleming model and a renewed version of it to match the empirical regularities mentioned in the introduction. ${ }^{33}$

\section{The Traditional Mundell-Fleming Model}

Leaving microfoundations aside, the widely used Mundell-Fleming or IS-LM-BP model is not fully able to reproduce all of the business cycle facts discussed above. Consider a fall in the world interest rate and a flexible exchange rate (see the left-side panel of Figure 14). ${ }^{34}$ The fall in $r^{w}$ leads to an increase in capital inflows that lowers the nominal exchange rate. Given that prices are sticky, the real exchange rate falls as well, causing a reduction in net exports. The IS curve shifts inward until the intersection with the LM at the new interest rate $r_{2}^{w}$. Lower net exports imply a lower output level. In turn, the reduced output induces lower imports, i.e., higher net exports. All in all, the effect on net exports is ambiguous. Consumption also declines due to the effect on income, whereas investment increases because of the lower interest rate. In conclusion, some 
predictions are at odds with actual data on EMDEs: the procyclicality of the interest rate, the countercyclicality of investment, and the possibly procyclicality, acyclicality or, at most, weak countercyclicality of net exports.

Consider a fall in the world interest rate under a fixed exchange rate (see right-side panel of Figure 14). This case is somewhat similar to an increase in current and future TFPs in the NP model. The fall in $r^{w}$ causes an increase in capital inflows, attracted to the economy by a higher domestic interest rate $\left(r_{1}>r_{2}^{w}\right)$. Given that the exchange rate is fixed, the central bank purchases foreign currency in exchange for domestic currency, which expands the money supply. This operation shifts the LM to the right, lowering the domestic interest rate to $r_{2}=r_{2}^{w}$. The lower interest rate stimulates investment and, therefore, output $\left(Y_{1}<Y_{2}\right)$. This latter effect, in turn, raises private consumption and imports, deteriorating the trade balance.
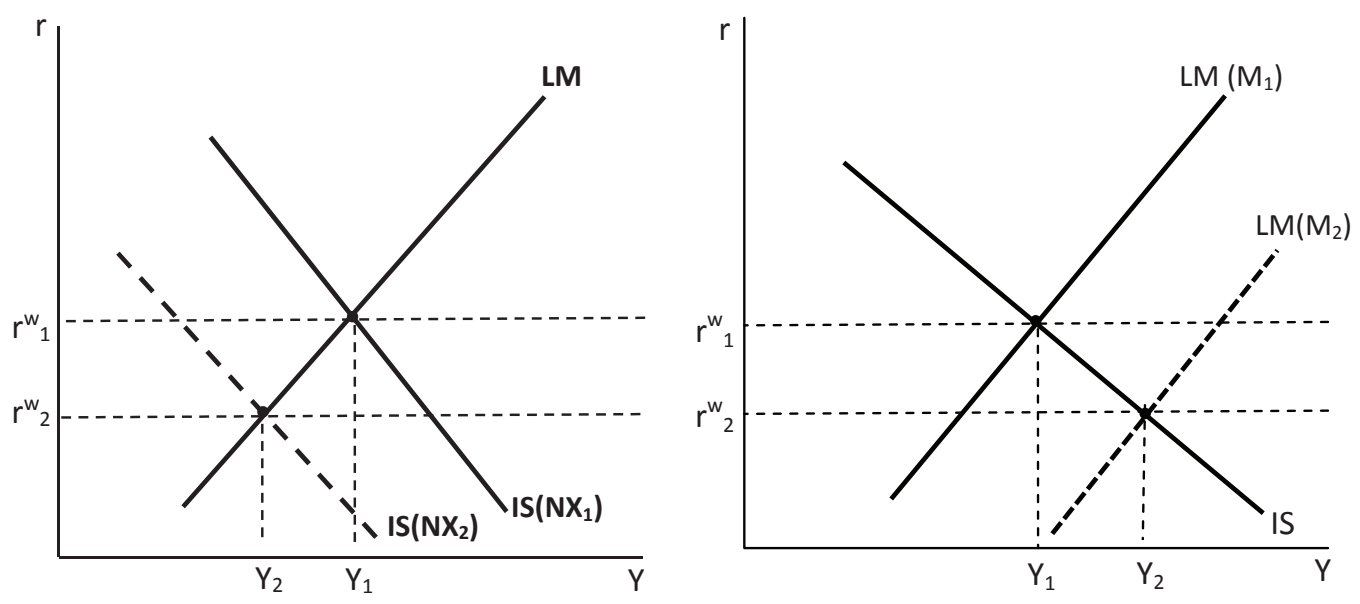

Figure 14: The traditional Mundell-Fleming model: A fall in the world interest rate under a flexible exchange rate (left side) and a fixed exchange rate (right side).

If the economy is regularly hit by this type of shock, under these assumptions, the model correctly predicts procyclical consumption and investment, and countercyclical interest rates and net exports. However, there are several issues. First, it is not clear how the real wage and employment react because the standard IS-LM-BP does not model 
a labor market. Under the usual assumption of wage stickiness, wages and, perhaps, employment would be acyclical. ${ }^{35}$ Second, the model seems to be unable to explain the higher volatilities of output, consumption, and the real wage in EMDEs. Third, prices are acyclical just by assumption (recall our discussion of the countercylicality of prices in previous section). ${ }^{36}$ Fourth, the main predictions of the model, such as the procyclicality of investment, depend on the exchange rate regime. As discussed before, the IS-LM-BP model works better when the nominal exchange rate is fixed. However, a number of EMDEs have moved towards more-flexible exchange rates or managed floating schemes, particularly after the 1997-1998 Asian Financial Crisis. ${ }^{37}$ Fifth, the same model would not be useful to understand business cycles in advanced countries. If the advanced economy has a floating regime, then we would observe the counterfactual predictions already discussed. If the advanced economy has a fixed regime and the emerging economy has a managed floating regime - which can be viewed as a midpoint case between the two graphs in Figure 14- then the model would predict that output volatility is greater in the advanced economy.

\section{The IS-LM-BP in the Pampas}

Céspedes, Chang and Velasco (2003) propose a microfounded version of the IS-LM-BP model for EMDEs. Their model includes balance-sheet effects caused by the inability of EMDEs to borrow in their own currencies in international credit markets, the socalled "original sin". The model is designed to address two important results. First, export demand shocks or world real interest rate shocks are amplified by the presence of balance-sheet effects. Second, if balance-sheet effects are sufficiently strong, then currency devaluations can be contractionary - a case that is discarded by the authors from an empirical viewpoint. 
Under a fixed exchange rate, the case analyzed by the authors, a fall in current exports lowers output and investment. This implies counterfactually procyclical net exports and an acyclical domestic interest rate. Similar effects on output and investment are obtained if there is an increase in the world interest rate. The difference is that the domestic interest rate is countercyclical and the consumption of imported goods can increase, making net exports also countercyclical. Price stickiness and the exchange rate regime lead to the acyclicality of prices and the nominal exchange rate. ${ }^{38}$ As in the case of the traditional IS-LM-BP, this model cannot account for the main differences in business cycle facts between advanced economies and EMDEs.

To conclude this section, we can say that, rather than trying to account for business cycle facts, the main usefulness of the IS-LM-BP models discussed previously relies on their ability to explain the effects of macroeconomic policies under different exchange rate regimes and financial distortions such as balance-sheet effects.

\section{Suggested Exercises}

1. A change in the world interest rate. Show that a reduction in the world interest rate is not sufficient to produce all of the predictions that we obtain from a persistent TFP fall in the NP model. This finding is consistent with theoretical simulations reported in Oviedo (2005) and Uribe and Yue (2006).

2. The macroeconomic effects of natural disasters. According to Raddatz (2007), climatic disasters (which include floods, droughts, extreme temperatures, and wind storms) result in declines in real GDP (per person) of $2 \%$ in low-income countries. This rate looks modest in absolute value, but the declines are significantly greater than the median growth rates of such countries $(0.4 \%)$. Analyze the macroeconomic effects of a climatic disaster that destroys part of the current stock of capital using the AG model. 


\section{Procyclical prices and monetary policy: The cases of Malaysia and Peru.}

In the fourth section, we show that if we extend the model with a money market, a persistent TFP increase that raises income and lowers the interest rate will contract money demand, causing a countercyclical behavior of the price level. However, there exists evidence that prices are procyclical in certain EMDEs such as Malaysia (Rand and Tarp 2002) and Peru (Castillo, Montoro and Tuesta 2007). In addition, several works conclude that monetary policy tends to be procyclical in EMDEs (see Kaminsky, Reinhart and Végh 2005, Duncan 2014). Show that if we include a procyclical monetary rule that positively links the money supply to output, $M^{s}=M^{s}(\underset{+}{Y})$, it is possible to observe an increase in the price level and, therefore, procyclical prices.

4. Does risk matter? Fernández-Villaverde, Quintana, Ramírez and Uribe (2011) show that changes in risk, measured by the volatility of the real interest rate, can account for the behavior of output, consumption, investment, and hours worked in Argentina, Brazil, Ecuador, and Venezuela. Suppose we extend the AG model by replacing the output demand equation by

$$
Y^{d}=C^{d}\left(\underset{-}{r}, \sigma_{r}, \ldots\right)+I^{d}\left(\underline{r}_{-}, \sigma_{r}, \ldots\right)+N X
$$

where $\sigma_{r}$ is the standard deviation of the real interest rate. The intuition behind the negative link is that an increase in $\sigma_{r}$ raises precautionary savings and, thus, lowers consumption. In addition, physical capital becomes riskier and, hence, investment falls. Analyze the effects of an increase in $\sigma_{r}$ on the main endogenous variables. 


\section{Notes}

${ }^{1}$ For example, according to Ahumada and Butler (2009) and Lora and Nopo (2009), the textbooks mostly used in Latin American countries are Sachs and Larraín (2002), Barro (1997), and Mankiw (2012), among others. For a more specialized textbook, see Montiel (2011). None of these includes a microfounded business cycle model for EMDEs. Barro (1997) has a closed-economy RBC model that is more suitable for understanding short-run fluctuations in a large, advanced economy. Textbooks authored or coauthored by Chilean economists such as De Gregorio (2012) and Sachs and Larraín (2002) do not contain a business cycle model for EMDEs.

${ }^{2}$ Pallage and Robe (2003) find that the welfare cost of consumption volatility in EMDEs is at least 10 times that in the United States. Calderón and Fuentes (2014) conclude that recessions are deeper, steeper and costlier among emerging market economies.

${ }^{3}$ Neumeyer and Perri (2005) report negative correlations between country interest rate and output for Argentina, Brazil, Korea, Mexico, and the Philippines. This finding has also been confirmed for other countries such as Ecuador (Li 2011), Chile (Céspedes and Chang 2007), Peru and South Africa (Uribe and Yue 2006). Hevia (2014) also finds country risk premium shocks can significantly account for business cycles in Mexico.

${ }^{4}$ For evidence on the last fact, see Li (2011) and Boz, Durdu and Li (2012). Except for fact \# (2), Curtis and Mark (2010) report similar empirical findings for the Chinese business cycle during the 1978-2007 period. Although the literature has placed more emphasis on emerging markets, Uribe and Schmitt-Grohé (2014) present evidence confirming that low-income, developing countries exhibit most of these characteristics as well.

${ }^{5}$ Many developing and emerging economies are net oil importers. A rise in the relative price of oil, an omitted input from a standard production function, can be modeled as a decline in total factor productivity (see Williamson 2013, chapter 12). Angelopoulos, Economides and Vassilatos (2011) address the role of institutional quality as a source of fluctuations in productivity to explain GDP fluctuations in Mexico.

${ }^{6} \mathrm{GHH}$ preferences lead to a labor supply that depends only on the real wage but not on consumption, and thus, wealth effects. This type of preference is widely used in the business cycles literature for EMDs. A short list includes Mendoza (1991), Neumeyer and Perri (2005), Oviedo (2005), Uribe and Yue (2006), Otsu (2008), Chang and Fernández (2010), García-Cicco, Pancrazzi and Uribe (2010), and Li (2011). 
${ }^{7}$ Of course, the parameters of the utility and production functions, and the depreciation rate are also exogenous.

${ }^{8} \mathrm{By}$ the Walras Law, the third market (the assets market) also should be in equilibrium.

${ }^{9}$ Strictly speaking, the arguments shown in the functions above are not the only ones. Preference and technology parameters are omitted. An alternative formulation could be, for example, $N^{d}=N^{d}(w, \ldots)$, to indicate that the function depends on other exogenous, perhaps less important, arguments.

${ }^{10}$ If Cobb-Douglas preferences were adopted, then the labor supply would depend also on consumption and, therefore, lifetime wealth and the real interest rate.

${ }^{11}$ Regardless of whether the individual is a net borrower or a net lender.

${ }^{12}$ One way to think about this is to rewrite the law of motion of capital as $I=K^{\prime}-(1-d) K$, where $K^{\prime}$ is the future stock of capital and $d$ is the depreciation rate. If $K$ diminishes, other things equal, then we should expect a rise in $I$.

${ }^{13}$ If the consumer is a net lender, an increase in the interest rate lowers current consumption provided that the substitution effect dominates the income effect.

${ }^{14}$ This is a simplification of the shocks introduced in the original AG model, which are stationary in TFP levels and nonstationary in labor productivity levels.

${ }^{15}$ Although it can be seen that current output is equally volatile, future output $\left(Y^{\prime}\right)$ is going to be less volatile because of the smaller changes in future TFP compared with the ones in EMDEs.

${ }^{16} \mathrm{An}$ intraperiod bond is one that is issued at the beginning of a period and its principal and interests are paid before the end of the same period. It only generates a financial cost in terms of an interest payment. It can be seen as an asset of very short maturity.

${ }^{17}$ It can be argued that this prediction is achieved just by construction because it is assumed that the risk premium depends on future TFP.

${ }^{18}$ If the output demand were steeper than the output supply in a closed economy, then we would observe counterintuitively that an increase in current TFP reduces output.

${ }^{19}$ It can be argued that the increase in $z$ also raises consumption and shifts the output demand to the right. This can be added to the figure. Given that the shift would be small compared with the shift of the output supply (due to consumption smoothing) and the results would be qualitatively similar, we prefer to omit it from this analysis. 
${ }^{20}$ This is easier to verify by simple inspection of equation (69) in Appendix B. If we set $\theta=0$ (no working-capital requirement) then the equilibrium level of labor $\left(N^{*}\right)$ does not depend on the real interest rate.

${ }^{21}$ There is a related literature of sudden stops and crises (see, e.g., Calvo, 2003). This hypothesizes a causal link from sudden stops to output drops. We restrict the analysis to the cases in which sudden stops are the result of a persistent negative TFP shock, most likely caused by problems of external solvency and the anticipation of a financial turmoil.

${ }^{22}$ In practice, the countercyclicality of the current account balance does not necessarily mirror the procyclicality of the capital account balance. It depends on the cyclical behavior of the change in international reserves.

${ }^{23}$ Assuming the same fraction $\theta$ in the working-capital requirement.

${ }^{24}$ Kraay $(2012$, 2014) also find government spending multipliers from nonsignificant to small values (0.4-0.5) for a set of developing countries.

${ }^{25}$ Alternatively, we can introduce public debt, $B^{g}$, and the following budget constraints: $G=T+B^{g}$ and $G^{\prime}=T^{\prime}+(1+r) B^{g}$. This more realistic formulation should not change the main conclusions of our exercise provided that the conditions of the Ricardian Equivalence Theorem hold.

${ }^{26}$ Backus and Kehoe (1992) show international evidence of the countercyclicality of prices after World War II in industrialized economies.

${ }^{27}$ To simplify the analysis, we set the inflation rate equal to zero; thus, the nominal equals the real interest rate.

${ }^{28}$ In this case, we assume that the monetary policy is acyclical or not used to stabilize prices. One of the suggested exercises in Appendix $\mathrm{C}$ addresses the (unusual) case of procyclical prices that might be understood if the central bank performs a (highly) procyclical monetary policy. Procyclical monetary policies are frequently observed in EMDEs (see, e.g., Kaminsky, Reinhart and Végh 2005).

${ }^{29}$ There also exists a large literature that tries to explain and verify the negative link by establishing a causal relationship from the nominal exchange rate to output in EMDEs. This is sometimes called the contractionary devaluation hypothesis. See, e.g., Kim and Ying (2007) and the references therein.

${ }^{30}$ Taylor (2002) finds that PPP holds in the long run for Argentina, Brazil, and Mexico during the 1870-1990 period. Calderón and Duncan (2003) find that PPP holds in Chile for the 1810-2002 period. 
${ }^{31}$ In this case, $e$ is endogenous. Naturally, the quantity of money $(M)$ becomes endogenous under a fixed exchange rate.

${ }^{32}$ Strictly speaking, we should include $N^{s}$ and $N^{s^{\prime}}$ in the consumer's problem and $N^{d}$ and $N^{d^{\prime}}$ in the firm's problem. To lighten the notation, we just use $N$ and $N^{\prime}$.

${ }^{33}$ Here we focus on models in the Keynesian tradition. Fernández-Villaverde, Quintana, Ramírez and Uribe (2011) propose a model that can be seen as a canonical SOE model extended with interest-rate volatility shocks. This is left as an exercise (see Appendix C).

${ }^{34}$ We consider here the case of perfect capital mobility. Similar results are obtained under imperfect mobility of financial flows. We also analyze other types of sources of fluctuations such as aggregate demand and monetary disturbances. We conclude that the case of interest rate shocks is the most relevant for our discussion.

${ }^{35}$ If wages are flexible, given that output is demand determined, then an increase in $Y$ would predict an increase in $N$ by the production function $Y=z F(K, N)$. The (potential) issue here is that the production function implies a labor demand that depends negatively on current total factor productivity.

${ }^{36}$ An extension of this model, such as the AD-AS, would predict procyclical prices under an upwardsloping aggregate supply.

${ }^{37}$ According to the classification of Ilzetzki, Reinhart and Rogoff (2009), the EMDES that adopted a more flexible exchange rate regime between 1997 and 1999 are Chile, Colombia, Brazil, Ecuador, Georgia, Indonesia, Kazakhstan, Liberia, Malaysia, Mauritius, Russia, Thailand, and Turkmenistan. Other countries with similar changes of regimes after 1999 are Argentina (2002), Armenia (2002), Dominican Republic (2000), Malawi (2000), Peru (2002), Philippines (2002), Sri Lanka (2002), Tajikistan (2000), and Turkey (2000). It is worth adding that Mexico let the peso float after the so-called Tequila Crisis in 1994.

${ }^{38}$ Under a flexible exchange rate, an increase in the world interest rate has ambiguous effects on the exchange rate, investment, and output. The model would need to be parameterized to obtain clearer effects. 